BNL 50558 $\theta-407$

BNL NORTHEAST ENERGY PERSPECTIVES STUDY

\title{
FUTURE NATURAL GAS SUPPLY TO THE NORTHEAST
}

\section{Richard N. Langlois}

\section{April 1976}

\section{POLICY ANALYSIS DIVISION}

NATIONAL CENTER FOR ANALYSIS OF ENERGY SYSTEMS

BROOKHAVEN NATIONAL LABORATORY

UPTON, NEW YORK II973 


\section{DISCLAIMER}

This report was prepared as an account of work sponsored by an agency of the United States Government. Neither the United States Government nor any agency Thereof, nor any of their employees, makes any warranty, express or implied, or assumes any legal liability or responsibility for the accuracy, completeness, or usefulness of any information, apparatus, product, or process disclosed, or represents that its use would not infringe privately owned rights. Reference herein to any specific commercial product, process, or service by trade name, trademark, manufacturer, or otherwise does not necessarily constitute or imply its endorsement, recommendation, or favoring by the United States Government or any agency thereof. The views and opinions of authors expressed herein do not necessarily state or reflect those of the United States Government or any agency thereof. 


\section{DISCLAIMER}

Portions of this document may be illegible in electronic image products. Images are produced from the best available original document. 


\title{
FUTURE NATURAL GAS SUPPLY TO THE NORTHEAST:
}

\author{
RICHARD N. LANGLOIS
}

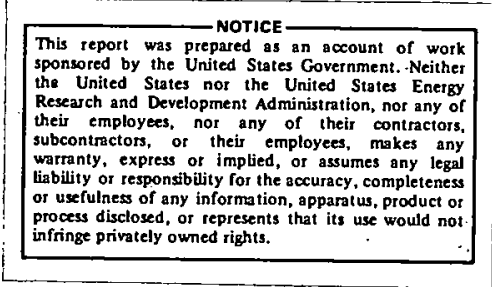

Work supported by the Division of Biomedical and Environmental Research of the United States Energy Research and Devclopment Administration under Contract No. E(30-1)-16 in the context of the Brookhaven National Laboratory Regional Energy Studies Program.

\section{POLICY ANALYSIS DIVISION NATIONAL CENTER FOR ANALYSIS OF ENERGY SYSTEMS BROOKHAVEN NATIONAL LABORATORY UPTON, NEW. YORK 11973}


This report was prepared às an account of work sponsored by the United States

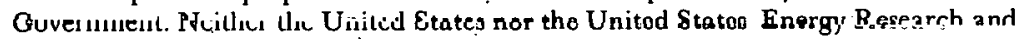
Development Administration, nor any of their employees, nor any of their contractors, subcontractors, or their employees, makes any warranty, express or implied, or assumes any legal liability or responsibility for the accuracy, completeness ö usefuliness of any information, apparatus, product or proness disrinser, nr represents that its use would not infringe privately owned rights.

Printed in the United States of America

Available from

National Technical Information Service

U.S. Department of Ciommerce

5285 Port Royal Road

Springfield, VA 22161

Price: Printed Copy $\$ 5.00$; Microfiche $\$ 2.25$

July 1976

750 copies 


\section{FOREWORD}

This report is one of a number of issue papers prepared as part of the Brookhaven National Laboratory Northeast Energy Perspectives study. The analyses in these papers were performed specificaliy to assist us in our first integrated study of the energy future of the northeastern United states.

Topics covered by the issue papers.include the potential supply of energy to the Northeast from coal, oil, natural gas, liquefied natural gas (LNG), nuclear power, municipal waste, solar energy, and wind power, and the demand for energy in the Northeast from the industrial, transportation, and residential and commercial sectors. In each case a range of estimates of energy supply or demand was constructed to reflect not only a variety of possible policy and technological developments, but also the basic uncertainties of all such future projections. The integrative analysis which relates the supply and demand picture is presented in "A Perspective on the Energy Future of the Northeast United States.".

The issue papers prepared for the Northeast Energy Perspectives study and the summary report will be available from:

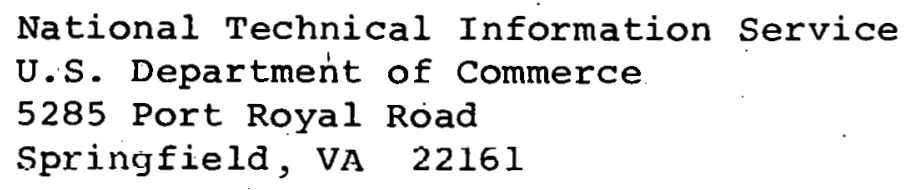

The issue papers and summary report are listed below. 
H. Bronheim, "Future Oil Supply to the Northeast United States," BNL 50557 (June 1976).

R. J. Goettle, IV, "Alternative Patterns of Industrial Energy Consumption in the Northeast," BNL 50555 (March 1976).

R. N. Langlois, "Future Natural Gas Supply to the Northeast," BNL 50558 (April 1976).

J. Lee, "Future Residential and Commercial Energy Demand in the Northeast," BNL 50552 (March 1976).

P. M. Meier and T. H. MCCoy, "Solid Waste as an Energy Source for the Northeast," BNL 50559 (June 1976).

P. M. Meier, T. H. MCCoy, and S. Rahmari, "Issues in the Future Supply of Electricity to the Northeast," BNL 50553 (June 1976).

B. S. Edelston and E. S. Rubin, "Current and Future Use of Coal in the Northeast," BNL 50560 (May 1976), Environmental Studies Institute, Carnegie-Mellon University, Pittsburgh, Penn.

V. L. Sailor and F. J. Shore, "The Future of Nuclear Power in the Northeast," BNL 50551 (March 1976).

G. R. Bray, S. K. Julin and J. A. Simmons, "Supply cf Liquefied Natural Gas to the Northeast," BNL 50556 (April 1976), Science Applications, Inc., 1651 old Meadow Road, McLéan, Va.

System Design Concepts, Inc., "Transportation Energy Consumption and Conservation Policy Options in the Northeast," BNL 50554 (April 1976), System Design Concepts, Inc., 9 Rector Street, New York, N.Y. I0006.

J. Brdiraral et al.; Editore, "A Perspective on the Fnergy Future of the Northeast United States," BNL 50550. (June 1976). 


\section{ABSTRACT}

The Northeast is heavily dependent on oil $(63 \% *)$ to meet its energy demand. The second largest fraction (18\%) is provided by natural gas. In 1972, the Region consumed 2.3 trillion cubic feet of gas, out of which $0.5 \%$ was imported from Algeria (as liquified natural gas) and Canada. About $3 \%$ was produced within the Region and about $96 \%$ came from the rest of the nation, mainly the Gulf Coast area. In terms of end use, the residential sector consumed the largest portion $(46 \%)$; only $5 \%$ was used in generating electricity (in contract to the national average of $20 \%$ ).

Due to the shortage of natural gas, especially on the interstate market, the Northeast has suffered curtailments of its firm-contract supplies in recent years. The curtailment priorities are regulated. by the Federal power Commission and the individual state based on end use mix as well as the amount of gas each pipeline company has available.

Nationwide gas production reached its peak of 22.6 trillion cubic feet in 1973 and has been declining ever since. This situation is further aggrevated by the two-tiered price structure. The disparity between interstate and intrastate gas prices gives the gas producing states a competitive edge in securing newly discovered gas reserves and results in the further shortage of natural gas available to other states. Partially because of this reason, the continued price regulation has become a very controversial issue.

Based on estimates of total U.S. gas reserves (discovered as well as undiscovered) and applying a modified Hubbert method to a

* All figures given are those of 1972 unless otherwise specified. 
number of assumptions, projections of natural gas production were made for 1985 and 2000. From these, the amount of gas supply available to the Northeast was projected based on further assumptions, e.g. if there is gas deposit on the Atlantic Outer Continental shelf, whether it will be developed in time, how much of the Alaskan gas is available to this part of the nation, etc. The conclusion is that under most scenarios the supply of natural gas to the Northeast will be severely constrained. 


\section{CONTENTS}

I.

II.

III.

IV.

$\mathrm{V}$.

VI.

VII.

VIII.

IX.

$\mathrm{X}$.

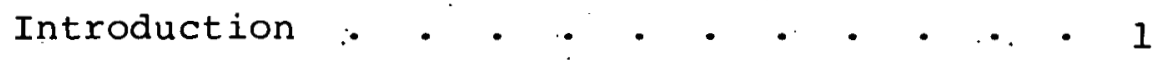

Curtailments • • • • • • • • • • • 3

Profile of: Northeast Gas Use. • • • • . 7

Overview of Domestic Natural Gas Industry. • 13

The Regulation Controversy . • • . . . 15

The Intrastate Versus Interstate Market • 19

The National Supply Situation. . . . . . . 23

Sources of Gas Within the Region. • • • 29

Scenarios of Northeast Gas Supply • • • • . 31

Sumnary • • • • • • • • • • . • • 35

Appendix A. Various Projections of Natural

Gas Supply • • • • • • 37

Appendix B. Some Causes of Natural Gas

Curtailment in the Interstate

Market. . . . . . . . 57

References . . . • . . • . • • • • 65 
1. Firm-contract curtailment by state • . • . . 4

2. Curtailment by pipeline • • • • • • • • • . 4

3. FPC end-use curtailment priorities . • . • • . 6

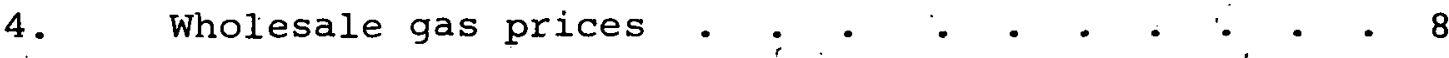

5. Retail gas prices, 1974 • • • • • • • • • • 8

6. Sources of gas to the Northeast, 1972 . • • • • 21

7. Net receipts from U.S. pipelines. • . . . . . 21

8. Summary of national natural gas production projections . : . . . . . . . . . . 28

9. Natural gas supply to Northeast . . . . . . . 33

A-1. Gas drilling escalation factors and projected gas well footage . • • • • • • • • • • • • 45

A-2. Project Independence sumnary of marketed natural gas production, lower 48 states . . . . . . . 49

A-3. Projected marketed gas production summary, Alaska . 53

A-4. Summary of projections for high (ACC) and medium

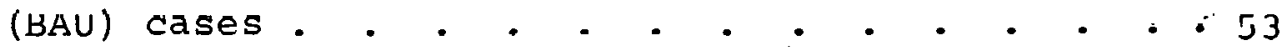

A-5. Summary of $Q_{\infty}$ projections . . . • • • • • • 55 
1. Energy use in the Northeast as a percentage of that

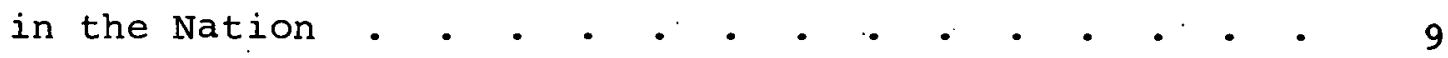

2. Comparison of gas end uses, 1972 - • • • • • • • • • 9

3. Comparison of fuel mixes, 1972. • • • • • • • • . 11

4. Historical national gas production . . . • • • • • 11

5. Interstate natural gas movements, 1970 . . • . . . 14

6. Gas flows to the Northeast, 1973 . . . . . . . . 14

7. Comparison of interstate and intrastate average annual additions to dedicated reserves : • . . . • . . 20

8. Some prominent recent national gas production projections 24

9. Summary of national gas production projections • • • 24

10. Annual reserve additions, historical and projected . . 28

11. Summary of national gas production projections, 1985 and 2000. . • • • • . • • • • • • • • • 28

12. Potential gas-producing areas in the Atlantic offshore

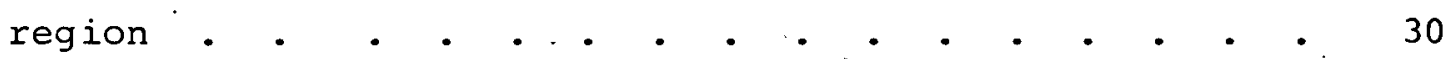

13. Summary of supply projections for Northeast.region : . 34

A-1. Typical logistic curves of cumulative production • • 41

$A-2$. The effect of skew on a Hubbert curve for fixed $Q_{\infty} \cdot \quad$ - 41

A-3. Hubbert curves, with PI BAU projections as data, skewed to pass through PI 1985 projection. . . . . . . . 51

$A-4$. Hubbert curves, with PI ACC projections as data, skewed to pass through PI ly8b projection.. • • • . • . . 51

$A-5$. Use of Hubbert curves to extend PI BAU Alaskan production projection . • • • • • • : • • • • 52

A-6. Use of Hubbert curves to extend PI ACC Alaskan

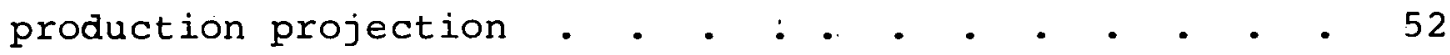

A-7. 1985 projection options for Project Independence cases . 56

A-3. Typical option diagram for year 2000 projections of marketed production 


\section{INTRODUCTION}

Memories of the 1973-74 oil embargo are particularly clear in the Northeastern United States. Since this region depended on foreign crude oil for $42 \%$ of. the refined petroleum products it consumed, it is no surprise that the embargo-induced need to rely solely. on domestic production and stored supplies became known as the energy crunch. Imports of natural gas, by contrast, constituted. only $0.6 \%$ of the supply reaching the Northeast in 1973, making the region (like the entire country) dependent almost exclusively on domestic production. Yet there is, according to recent estimates, only roughly as much gas as oil (compared in terms of heat value). left to be recovered in the United States. Indeed, the gas supply situation in this country is coming increasingly to be regarded as a natural gas crunch, which, like its oil-embargo, counterpart, crunches hardest upon the Northeast.

The natural gas section of this study addresses this increased awareness of gas supply shortage by presenting a background profile of the natural gas situation in the region and the Nation. In addition, this study will deal with supply prospects in the future - notably the years 1985 and 2000-and will delineate some of the policy considerations that may influence future supply.

*Estimate is for 1972, the base-year of this study. ${ }^{1}$ 


\section{THIS PAGE}

WAS INTENTIONALLY

LEFT BLANK 


\section{CURTAILMENTS}

The problem can be stated simply. In the Northeast, as in other parts of the country, the demand for natural gas is out distancing the available supply. The most palpable effect of this supply-demand imbalance has been. the curtailment of supply to distribution companies (gas utilities) by the interstate pipe line companies that ship the gas from the well. During the winter of 1974-75, for example, the pipeline companies fell short by 168 billion cubic feet (BCf) of "firm-contract" gas. 2,5 This means that gas utilities were short by 168 BCf in the amount they needed to service all holders of firm or non - interruptible contracts.

However, supplies to most firm-contract consumers were not actually curtailed: Data are difficult to get, but one survey of state agencies indicates that few if any individual firm customers' supplies were shut off. ${ }^{3}$ The 168 BCf curtailment of the utilities' gas last winter was largely balanced by supplements from other sources, usually imported gas or gas synthesized from petroleum feedstocks such as naphtha.

The curtailment of firm-contract gas is in addition to the curtailment of gas intended for holders of interruptible contracts. . Interruptible-contract consumers, usually industries, have the capability of using other fuels; their interruptible status gains them reduced rates at the expense of occasional interruption. In the last few years, as the utilities' supply has worsened, these occasional interruptions have lengthened into the entire winter season in most of the Northeast region. 4

Table 1 gives a breakdown of firm-contract curtailments by state. 
Table 1

FIRM-CONTRACT CURTAILMENT BY STATE ${ }^{2}$ (BCf)

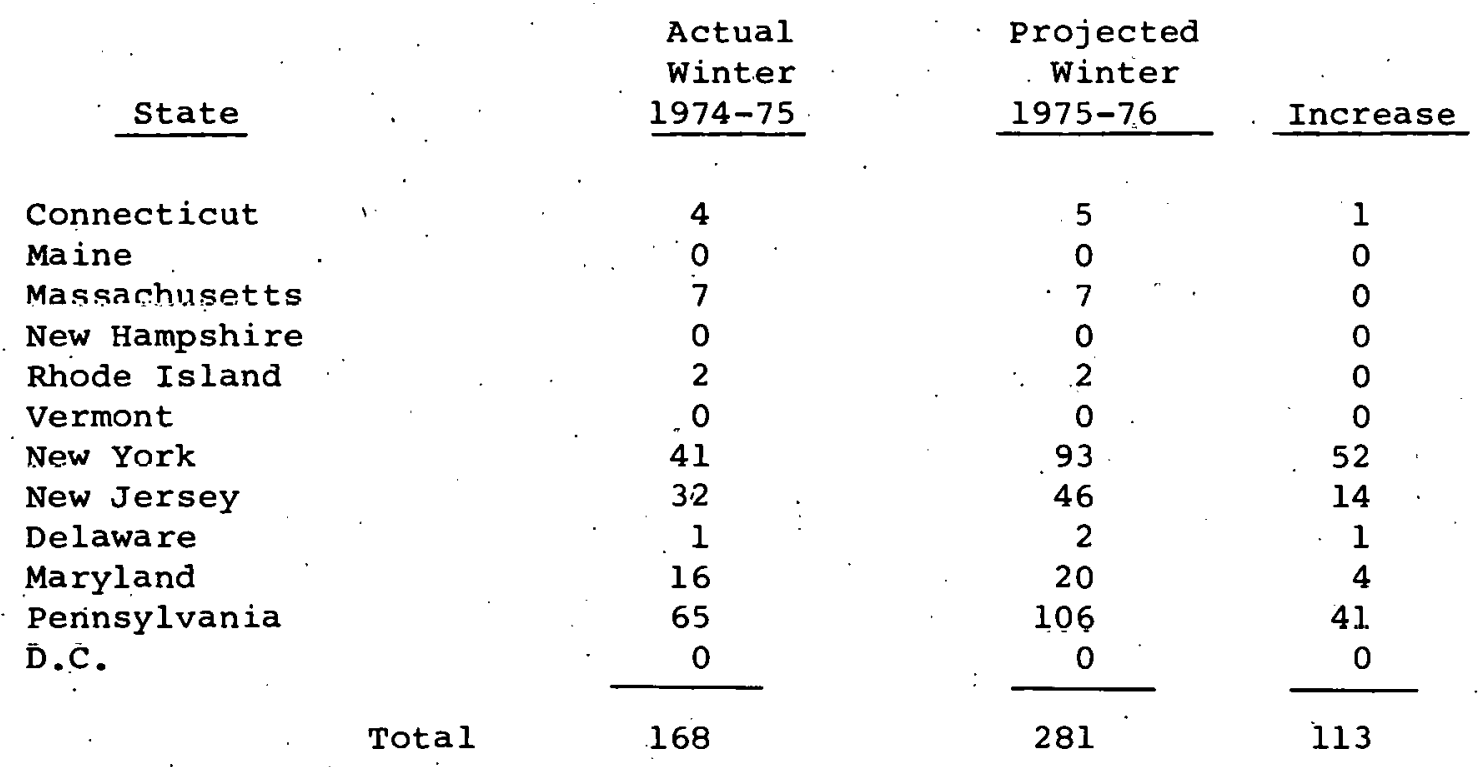

Talile 2

CURTA ILMENT BY PIPELINE 5,6 (BCF)

Actual

Projected

Winter Winter

Pipeline

1974-75

1975-76

Culutulia

182

Texas Eastern

99

2II

119

$2 y$

Tenneco

84

95

20

Transron

124

Total

489

$\lcm{170}$

11

46

595

106 
The four interstate pipeline companies 1 isted in Table 2 are the main suppliers of gas to the region (the smaller pipe lines within the region receive their gas from these larger companies). The Northeast bore $37 \%$ of these companies' curtailments during the 1974-75 heating season. Between October 31, 1970, and March 31, 1975, curtailments of firm-contract gas alone have totaled 4.5 trillion cubic feet (TCf). 2

The Federal Power Commission (FPC) has jurisdiction over the curtailment of supplies to distribution companies and to industries that buy gas directly from the interstate pipelines; individual state regulatory bodies have control over the curtailment of supplies to individual end users by the distribution companies. FPC regulation is prediated on an end-use curtailment plan (see Table 3). In effect, the amount of gas a distributor receives is based on the end-use mix represented by its customers as well as on the amount of gas its supplier has available. The manner in which each individual gas utility. apportions gas to consumers is not regulated by this FPC curtailment plan. More detailed information on curtailment policies at the state level for regulating distribution apportionment to end users is given in refs., 3 and 7 . The typical curtailment plan is either an FPC-like end-use or a pro rata plan.

Whether gas utilities in the Northeast will continue to be able to meet demand with imports and synthetics is unclear. Interstate pipeline curtailments look to be increasing in the near future, and this has led some proponents of deregulation, including president Ford, ${ }^{3}$ to assert that, beginning this winter (1975-76), utilities will no longer be able to meet the requirements of firm-contract. customers and will be forced to shut off supplies to consumers with no capability for using alternate fuels. Some possible causes of the curtailment of natural gas in the interstate market are outlined in. Appendix B. 
FPC END-USE CURTAILMENT PRIORITIES (FROM FPC Order 467-B, MARCH 2, 1973)

(Listed in order of decreasing priority, i.e.. first group

listed is last to be cut off)

1. Residential; small commercial (<50 Mcf*/peak day).

2. Large commercial ( $\geq 50 \mathrm{Mcf} /$ peak day); firm-contract industrial requirements for plant protection, feedstack, and process needs; pipeline customer storage injection; firm industrial sales up to $300 \mathrm{Mcf} /$ day.

3. All industrial requirements not specified in items. 2, 4, 5, and 6 .

4. Firm-contract industrial requirements for boiler fuel use at $<3000 \mathrm{Mcf} /$ day but $>1500 \mathrm{Mcf} / \mathrm{day}$, where alternate fuel

capabilities can meet such requirements.

5. Firm-contract industrial requirements for large volume $(\geq 3000$ Mcf/day) boiler fuel use where alternate fuel capabilities can meet such requirements.

6. Interruptible requirements $>300 \mathrm{Mcf} /$ day but $<1500 \mathrm{Mcf} /$ day, where alternate fuel capabilities can meet such requirements.

7. Interruptible requirements of intermediate volumes (from $1500 \mathrm{Mcf} / \mathrm{day}$ to $3000 \mathrm{Mc.f} / \mathrm{day}$, where alternate fuel capabilities can meet such requirements.

8. Interruptible requirements $>3000 \mathrm{Mcf} /$ day but $<10,000 \mathrm{Mcf} /$ day. where alternate fuel capabilities can meet such requirements.

9. Interruptible requirements $>10,000 \mathrm{Mcf} / \mathrm{day}$, where alternate fuel capabilities can meet such requirements.

* MCf $=$ thousand cubic foet 


\section{PROFILE OF NORTHEAST GAS USE}

In order to understand the implications of the current supply situation, one should recognize the unique position of the Northeast region within the national gas system. One of the most significant ways in which the region differs from the rest of the country is in the prices it pays for natural gas. Tables 4 and 5 show wholesale and retail prices both within and without the region. Prices in Northeastern cities are systematically higher than in other parts of the country, because of both transmission and distribution costs. The higher transmission cost is due simply to the distance between this region and the source of supply. The increased distribution cost is more difficult to explain, but is due partly to the use of higher priced imported and synthesized gases by utilities in the Northeast to supplement pipeline supplies.

The high price of gas is one of the factors that have shaped the use pattern in the region (Figure 1). Whereas the region houses $>26 \%$ of the Nation's population and consumes almost $22 \%$ of the country's resources, it receives only about $10 \%$ of national natural gas production.

The apportionment of this gas among types of end use is also characteristically different from the national norm (Figure 2). Almost half the gas sold in the region is for residential consumption, compared with a national average of 30\%. This tendency toward residential use of gas and away from its use as a boiler fuel by industries and electric utilities is a tendency toward what the FPC calls high priority uses.

This means that there is little flexibility in the region's gas consumption profile; curtailment of supplies would cut into high priority industrial, commercial, and eventually residential requirements more quickly in the Northeast than in other parts of 
Table 4.

WHOLESALE GAS PRICES ${ }^{7} 9$ (PRICES PAID TO PIPELINE COMPANY BY DISTRIBUTOR, \&/MCf)

1973

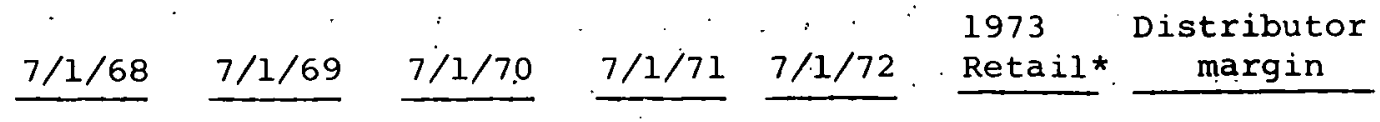

In Region

\section{Boston}

Washington

Philadelphia

Baltimore

New York

Outside Region

Chicago

San Francisco

Los Angelés

Minneapolis

$\begin{array}{ll}61 / 34 & 69.21 \\ 46.71 & 46.71 \\ 41.86 & 43.56 \\ 41.58 & 41.58 \\ 40.73 & 41.63\end{array}$

68.39
49.73
43.69
44.73
43.69

76.17

61.64

46.90

52.60

45.98
217.0

138.7

143.5 .

138.7

$163: 9$
140.27

78.41

90.22

85.48

111.97

* Prices paid to distributor by consumers; in this case residential: consumers. Retail price may also reflect a more expensive admixture of imported and/or synthetic gas.

$\begin{array}{lllllll}29.61 & 29.12 & 33.31 & 36.04 & 36.65 & 108.63 & 71.98 \\ 28.13 & 29.71 & 33.28 & 35.17 & 36.52 & 77.60 & 41.10 \\ 29.24 & 30.85 & 36.98 & 38.78 & 40.74 & 76.60 & 35.86 \\ 35.46 & 36.72 & 36.29 & 42.59 & 45.14 & 99.90 & 54.76\end{array}$




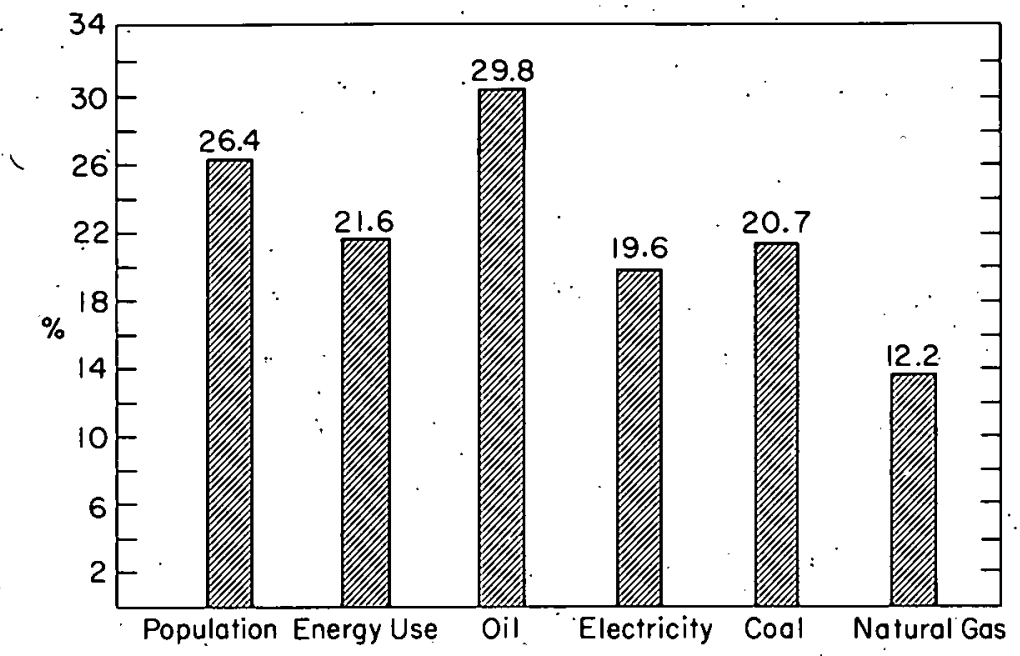

Figure 1. Energy use in the Northeast as a percentage of that in the Nation. 1
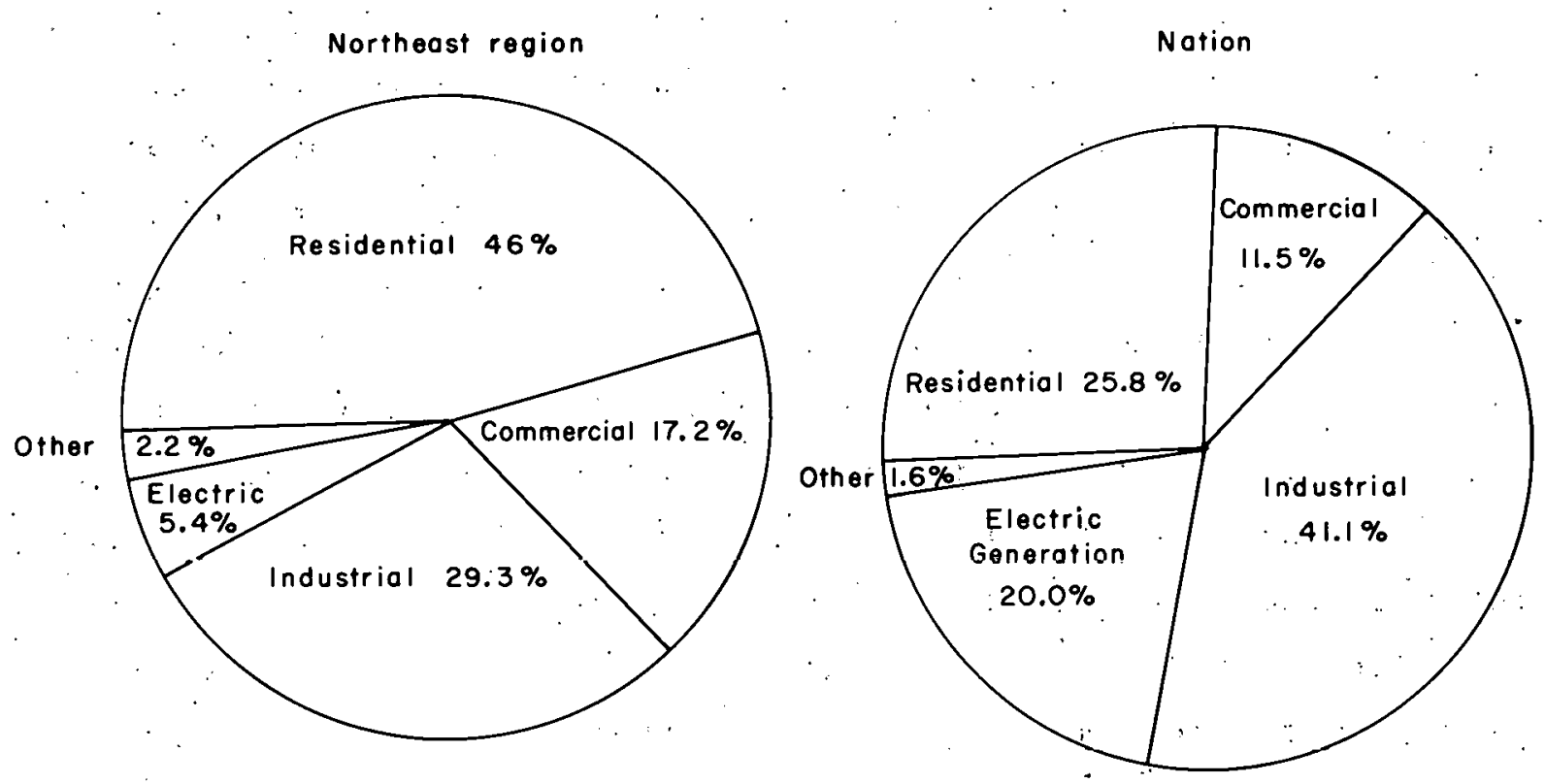

Figure 2. Comparison of gas end uses, 1972. ${ }^{19}$ 
the country. Consider use by electric utilities, which the FPC considers low priority and is trying to discourage: of the gas used for electricity generation in the U.S.' in 1972, the Northeast consumed only $3.1 \%$, whereas the states of Texas, Louisiana, and Oklahoma consumed > $48 \%$. 9

The short supply and high price of gas in the northeast not only have brought about a pattern of high priority end use but also have contributed to the region's heavy dependence on oil. Figure 3 shows how the Northeast satisfies its energy demands. Oil provided $63 \%$ of the energy in 1972, but gas, despite the small share of the Nation's eupply coming to the region, provided the second-largest fraction of the energy, 18\%. Clearly, natural gas is an important part of the regional energy picture, and gas shortages would pose serious problems concerning the possibility -- and desirability-of fuel substitution.

An investigation of the problem of gas shortage must begin with the source of $95 \%$ of the region's current pipeline supply, the domestic natural gas industry. Figure 4 shows natural gas production in the Nation during the last 15 years. Up to 1970 , the amount of gas produced increased fairly steadily; then the rate of increase slowed down for 3 years. In 1973, total marketed production reached a peak of 22.7 Tcf. In 1974, for the first time in half a century, gas production declined from the previous year. Figures for the first 3 quarters of 1975 indicate a further $10 \%$ drop from the 1974 level. 23

Furthermore, until 1967, the amount of gas discovered each year exceeded the amount produced in that year. Since then, the reverse has becn truc, crccpt for 1970, whon gas was discovered in the Prudhoe Bay area of Alaska. 12 

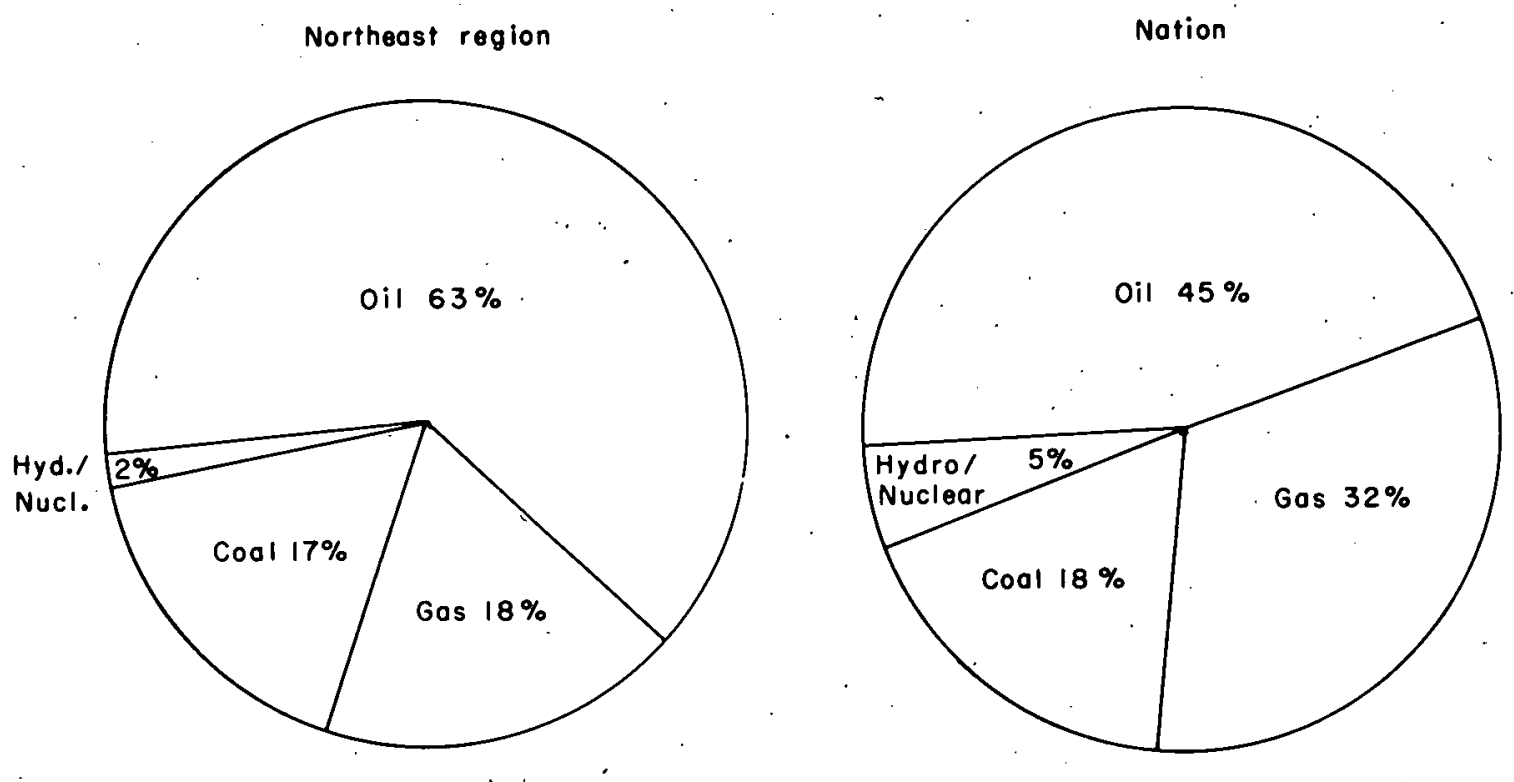

Figure 3. Comparison of fuel mixes, $1972 .^{1}$

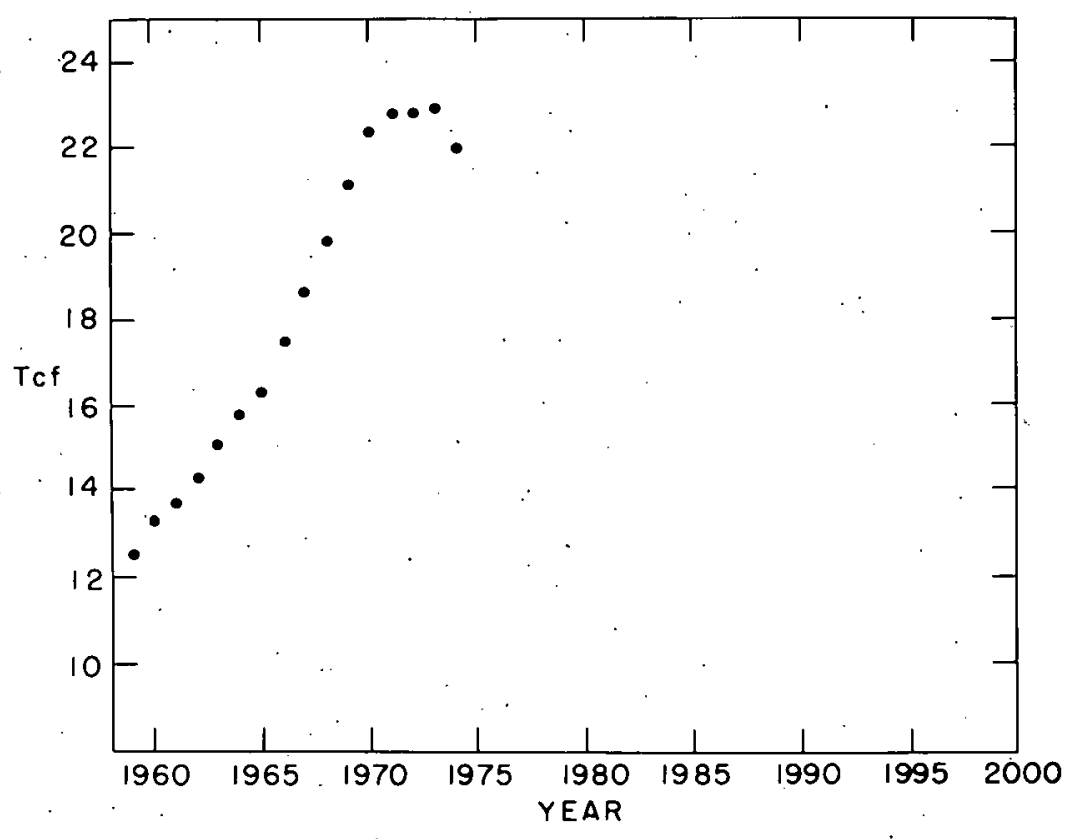

Figure 4. Historical national gao production. 20 


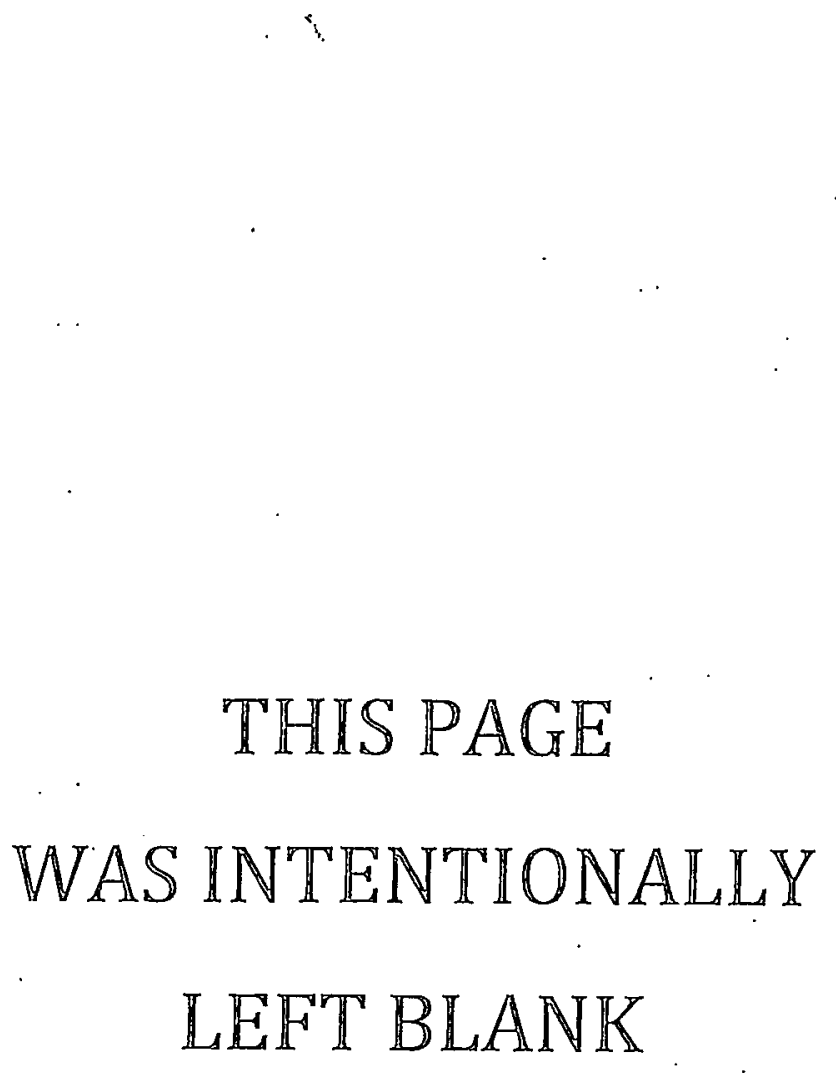




\section{OVERVIEW OF DOMESTIC NATURAL GAS INDUSTRY}

Figure 5 shows the flows of natural gas from producers to consumers; Figure 6 shows that 95\% of the gas reaching the Northeast originates in the Texas-Louisiana Gulf Coast area; either on or offshore.

As it comes from the ground, natural gas is primarily methane (the simplest hydrocarbon) with small amounts of more complex hydrocarbons such as ethane, propane, and butane, which are usually removed and sold separately, so that the marketed gas is almost pure methane. The chemical simplicity. of natural gas accounts in part for its increased popularity in recent years. Unlike coal or oil, methane is a negligible producer of sulfur oxides or particulate emissions. Although gas does produce measurable amounts of nitrogen oxides during combustion, it has a much smaller overall environmental effect than do alternative hydrocarbon fuels and is therefore a logical substitute for coal and oil in the face of environmental control laws.

Gas is brought from ground to consumer by a three-stage national gas industry: the producing company, which removes the gas from the ground; the pipeline company, which transports it to distribution points; and the gas utility, which is the final distributor. The distinction between these stages is sometimes blurred, as a single company often has a financial interest in two or more of them; but the U.S: natural yás system can be visualized as hourglass shaped, with a few major pipeline companies (and $\sim 100$ smallex pipelines) connecting thousands of producers with thousands of distributors.

The importiant distinction between pipelines is whether or not . they cross state boundaries. Interstate pipelines fall under Federal control and are regulated by the FPC as required by the Natural Gas Act of 1938. Companies that operate purely intrastate are not subject to Federal regulation. 


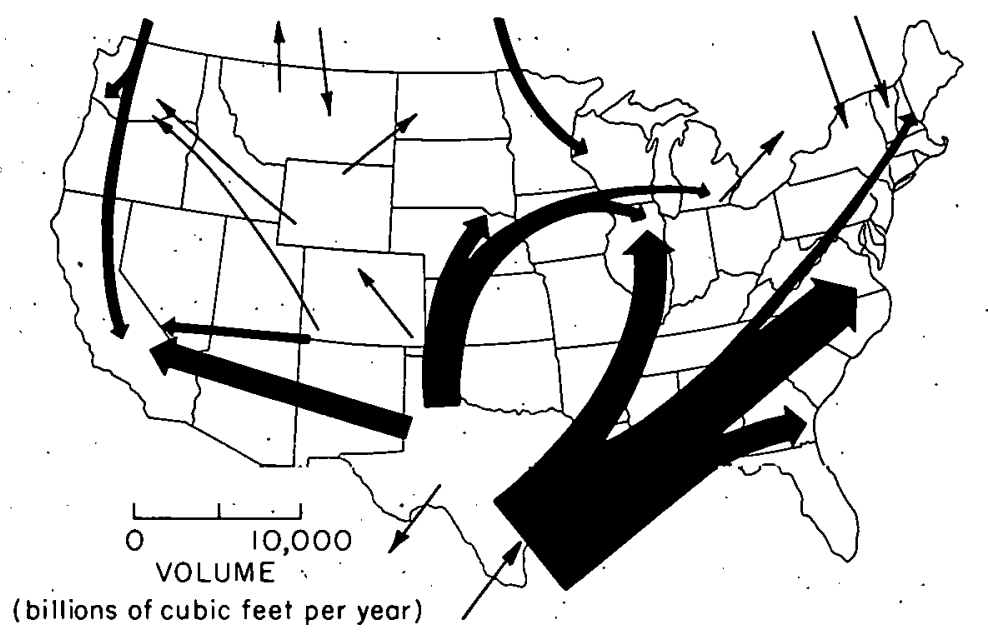

Figure 5. Interstate natural gas movements, $1970 .^{9}$

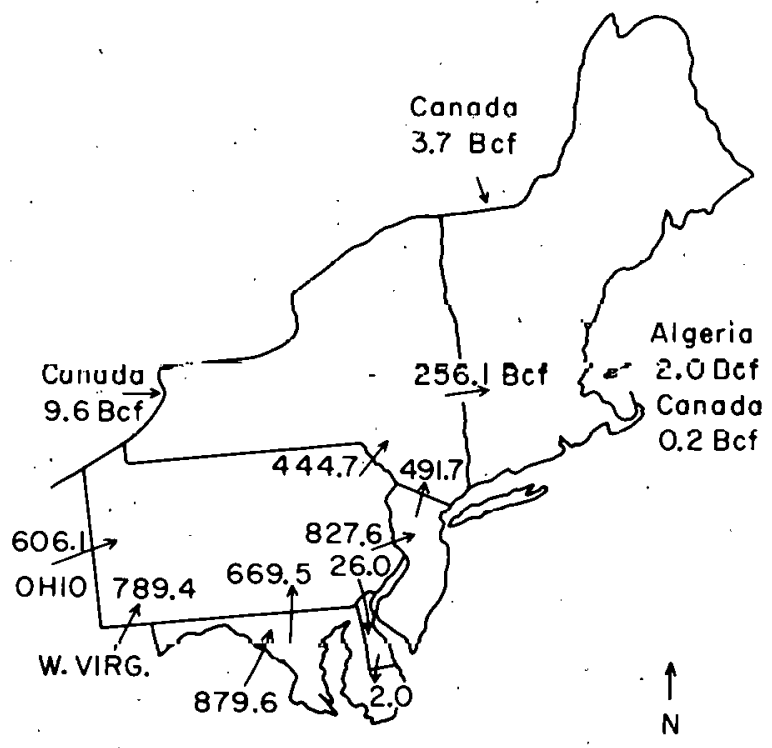

Figure 6. Gas flows to the Northeast, 1973. ${ }^{19}$. 


\section{THE REGULATION CONTROVERSY}

The most controversial aspect of FPC regulation is control of the price that producers may charge the interstate companies, the wellhead price of the gas. Regulation has kept the price at levels described as artificially low in both industry ${ }^{10}$ and FPC ${ }^{14}$ writings.

Some people consider the low price responsible for the decline of gas production in the last few years because, they argue, low price has made gas attractive to the consumer (thus increasing demand) while decreasing the producers! incentive to explore for new sources or to develop marginally productive fields (thus reducing production). They therefore advocate deregulation of wellhead price and return to a free-market system in order to let prices rise and demand fall so that incentives to producers as well as supplies would increase, the ultimate result being equilibrium between supply and demand.

Other people look upon the current gas shortage as having nothing to do with price regulation, being merely the result of monopolistic practices by the industry, a manufactured shortage designed to force higher prices in unregulated markets and thus to win increased prices or deregulation from the Government. critics have accused the industry of understating reserves and interrupting production in order to influence the debate over price regulation.

A third group considers the problem to be more technological and geological than economic. In their opinion, both supply and demand are inherently insensitive to price at this stage in the exploitation of domestic gas potential, and a price increase, which would be inflationary and also hard on consumers, would neither markedly reduce the demand for gas nor increase the available supply. 
Each of these thrée perspectives implies a different policy choice. If the shortage is regulation induced, then deregulate wellhead prices. If the shortage is monopoly induced, then stand firm on price controls and take legal action against the monopolists. If the shortage is not an economic problem at all, then keep consumer prices as low as possible while intensifying efforts at securing gas from alternative sources (offshore and Alaskan production, synthesized or imported gas).

It is interesting that the Federal Power.Commission itself is in favor of deregulating gas price. 12 The FPC thinks that the current shortage is a direct result of regulation, and that the price of gas will continue to rise even under the present system. Either because of underutilization of pipeline facilities or because of the introduction of high-cost supplementary gas supplies such as substitute natural gas or liquified natural gas. According to the FPC, since gas cost will rise with or without deregulation, the public would be better served under deregulation, which would lessen the traumatic burden of continuing gas shortages by tending to restore the competitive position of the interstate sector and thus making greater supplies available to both interstate and intrastate customers. "But with deregulation must come an assurance of protection of the public interest. Prices must be reported regularly and monitored to make certain that producers do not use the present shortage situation as an opportunity to indulge in practices which result in restraint of trade. There must be strict surveillance by the FPC, the Department of Justice, and other agencies, and strict enforcement of antitrust laws to safeguard against anticompetitive conduct in any market area." 12 The FPC further states that, if the deregulation of wellhead price cannot be achieved, at least the Natural Gas Act must be amended to authorize the FPC, in setting rate levels, to go beyond 
"current costs" and consider other economic and market factors, including the prices of competitive fuels and alternate sources of supply. The FPC hopes that in this way the demand for natural gas will be decreased even though the supply will not be increased. 
THIS PAGE

\section{WAS INTENTIONALLY LEFT BLANK}




\section{THE INTRASTATE VERSUS INTERSTATE. MARKET}

The intent of this report is to describe, not to resolve, the complex issues involved in price regulation. There is, however, one effect of. controls that is universally agreed to be deleterious to interstate (and consequently Northeastern) gas supply.

Since gas sold within the boundaries of the state that produced it is not subject to FPC regulation, producers can easily receive significantly higher prices by selling to intrastate rather than to interstate pipelines, which consume about $70 \%$ of all natural gas. produced in the U.S. The exact level of prices paid within the intrastate market is difficult to determine. One estimate puts the average wellhead price at $\$ 1.25$ per thousand cubic feet (Mcf), ${ }^{10}$ and a spokesman for President Ford has claimed that prevailing prices are closer to $\$ 2 / \mathrm{MCF}$, whereas the price allowed for sales to interstate pipelines is $52 \mathrm{c} / \mathrm{Mcf}$ (which roughly corresponds to $\$ 3 / \mathrm{bbl}$ of oil in terms of heat content.)

The net effect has been to give the intrastate companies a competitive edge in securing dedications of newly found gas reserves. Figure 7 demonstrates the recent upsurge in their acquisition of new supplies.*

* Usually when gas reserves are discovered, after their extents and productive characteristics have been proved, they are promptly committed by the producers to pipeline companies, interstate or intrastate, under long-term (e.g., 20-year) gas purchase contracts. In recent years, because of the shortage, interstate pipeline companies have been making advance payments to producers to explore new reserves, and, in return for these interest-free loans, hold the exclusive right to negotiate for any gas discovered. Statistics on the gas supplies dedicated to interstate pipelines are reported to the FPC by each company on FPC Form 15.12 


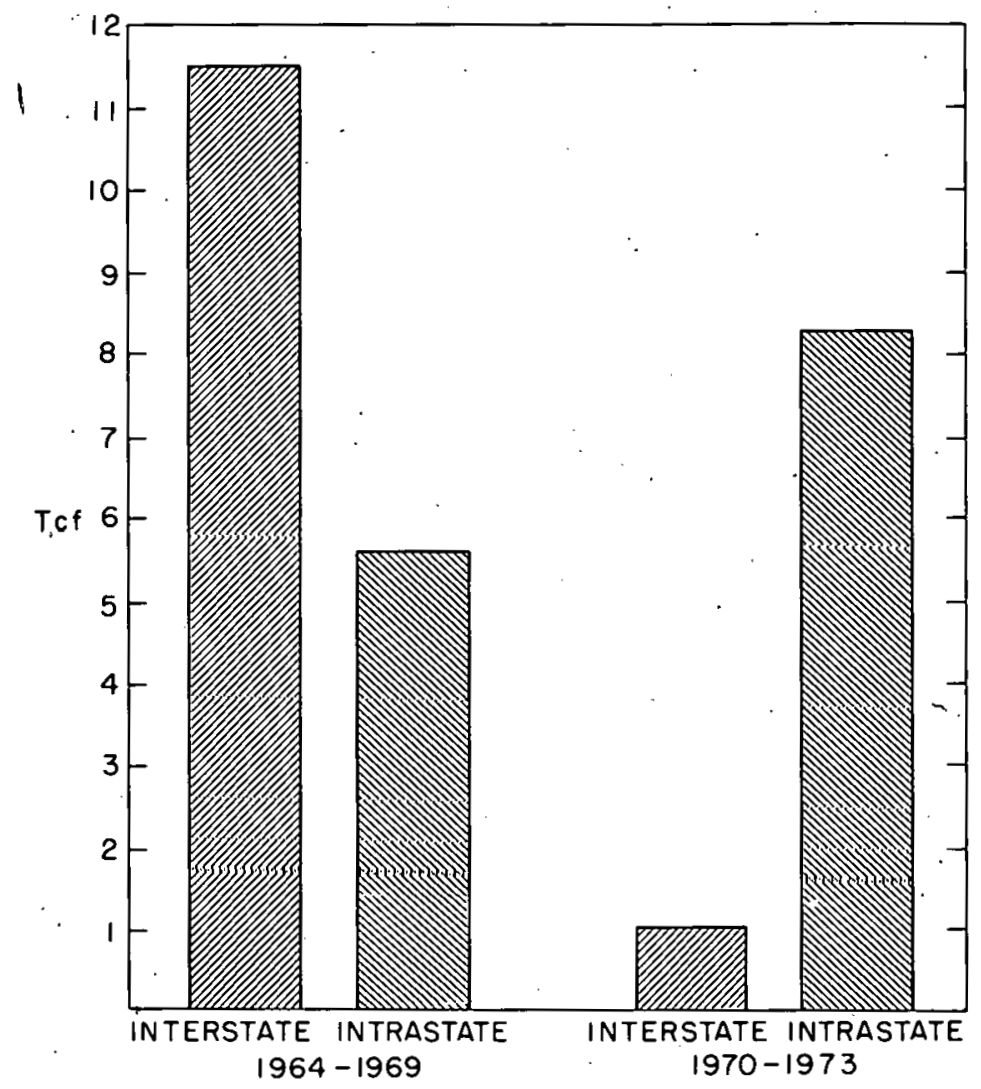

Figure 7. Comparison of interstate and intrastate

Frnm the viewpoint of the Northeast, which relies almost exclusively on the interstate system (Table 6), ruyulation has given the gas shortage a double-barreled character: not only is total production declining (since 1974) but also the share of it reaching the Northeast (Table 7). The share of total national production received in the regiun dropped by $>0.3 \%$ bctween 1971 and 1973; an extrapolation of that trend would lower the region's share to $9.4 \%$ by 1980 . In contrast, the percentage share of interstate gas received by the Northeast shows no clear trend; r in fact, in 1972. the region's share of interstate gas was rising while its share of total production was falling. 


\section{Table 6}

SOURCES OF GAS TO THE NORTHEAST, ${ }^{19} \quad 1972$

$\begin{array}{rc}\text { Ouantity (BCf) } & \% \text { of Total } \\ 77.9 & 3.3 \\ 10.1 & 0.4 \\ 2.0 & 0.1 \\ 2248.1 & 95.2 \\ 2338.1 & 100.0\end{array}$

Table 7

NET RECEIPTS FROM U.S. PIPELINES (CONSUMPTION AND LOSSES) NOT INCLUDING

IN-STATE PRODUCTION OR IMPORTS AND EXPORTS ${ }^{19}$ (BCF)

In-region production

Imports from Canada

Imported from Algeria

Gas from interstate pipelines

Total
2338.1

$\begin{array}{lrrrrrr} & \frac{1968}{1969} & \frac{1969}{1970} & \frac{1971}{1972} & \frac{1973}{19.9} \\ \text { Conn. } & 55.3 & 59.4 & 62.4 & 62.9 & 66.9 & 63.9 \\ \text { Mass. } & 136.9 & 138.4 & 147.5 & 155.5 & 164.5 & 154.0 \\ \text { R.I. } & 21.4 & 23.1 & 26.1 & 25.7 & 23.5 & 20.8 \\ \text { Vt. } & (1.5) & (2.1) & (2.5) & 12.8) & (3.7) & (3.9) \\ \text { N.H. }+ \text { Me. } & 5.7 & 7.6 & 8.4 & 9.6 & 10.3 & 10.4 \\ \text { N.Y. } & 643.3 & 686.4 & 701.1 & 731.2 & 674.3 & 689.8 \\ \text { Penn. } & 668.7 & 730.6 & 763.2 & 764.9 & 766.6 & 771.9 \\ \text { N.J. } & 281.2 & 316.8 & 334.0 & 341.5 & 332.9 & 304.3 \\ \text { Md. D.C. } & 155.8 & 166.1 & 187.7 & 194.3 & 212.1 & 205.0 \\ \text { Del. } & 24.3 & 25.6 & 26.9 & 26.9 & 24.0 & 23.5 \\ & 1992.5 & 2134.0 & 2257.1 & 2312.6 & 2248.1 & 2243.4\end{array}$

Net U.S. production (TCF)

19.8

21.2

22.4

22.8

22.8

22.9

Region as \%

10.1

10.1

10.1

10.1

9.9

9.8

\footnotetext{
a LNG imports from Algeria and Canada removed.

$\mathrm{b}$

All gas to vermont is from Canada.

C

Imports from Canada removed.
} 


\section{THIS PAGE}

\section{WAS INTENTIONALLY}

LEFT BLANK 


\section{THE NATIONAL SUPPLY SITUATION}

The ability of distributors in the region to meet demand will depend on the availability of supply. from the national system. As shown in Figure 8;, the future of national supply is not at all certain. This maze of projections is reviewed in some detail in Appendix A; only selected projections are discussed here (Figure 9).

The high and middle cases are two Project Independence (PI) scenarios, 11 accelerated (ACC) and business as usual. (BAU). The latter requires no new government policies or actions other than deregulating wellhead gas price, but the former requires more. The low case is the conservative realistic case of the FPC's National Gas Survery.

The PI projections were made in 1974. The methodology used by both the oil and gas task forces was a modification of that used by the National Petroleum Council (NPC). Essentially, assumptions were made on leasing policies and schedules, drilling rates, finding rates, and percentage of gas produced from new reserves. This was done for each NPC region separately.

The basic differences between the BAU and the ACC case result from (a) different timing and magnitude of offshore lease sales and (b) higher drilling escalation in the ACC case. For example, for the BAU case, it is assumed that 3 mililion acres of outer continental shelf (OCS) would be offered for leasing through 1990 and $55 \%$ of that offered would actually be leased. This is roughly consistent with: the current leasing schedule published by the Bureau of Land Management. (BLM). In contrast, the assumed leasing program for the ACC case called for an offering of 3 million acres 


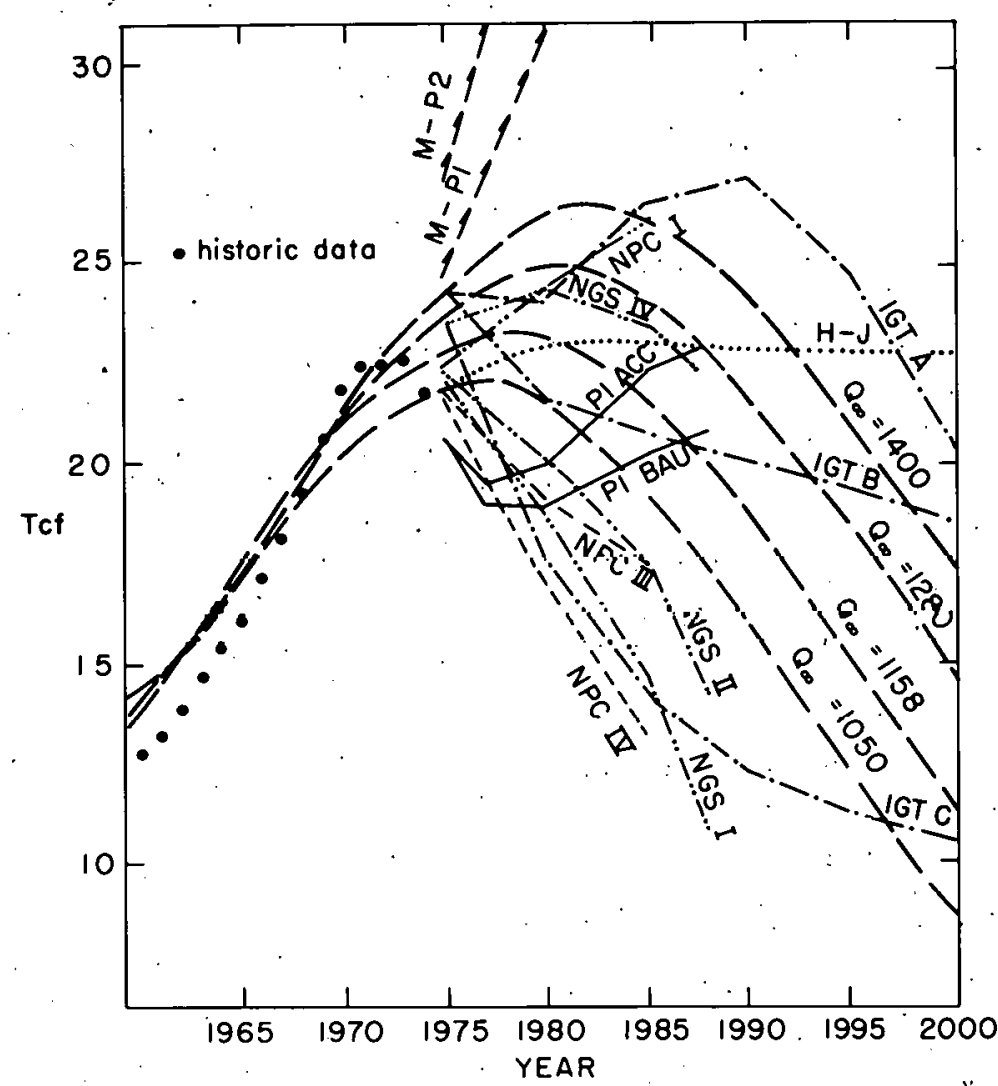

Figurè 8. Some prominent recent national gas production projections. $25,27,30,32,34,35$

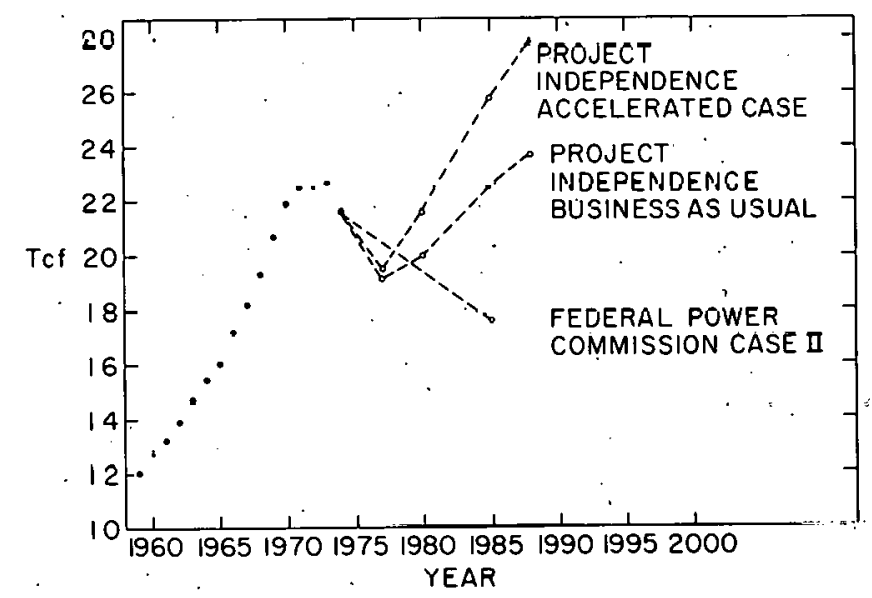

Figure 9. Summary of national gas production projections. 
of ocs in 1977; increased to 10 million by 1990 . again with $55 \%$ leased. Under this assumed schedule, for the full 1974-1990 period, 106 million acres would be offered and $~ 50$ million acres actually leased; this is $>6$ times the amount of alil ocs:land leased through the end of 1973. By 1985, much of the increase in drilling between the two cases is allocated to the three offshore areas.

Higher drilling rates are used in the ACC than in the BAU case (see Appendix A, Table $A-1$ ), but the finding rate and the percent reserve produced are assumed to be the same for both cases. The resulting reserve additions and productions are given in Figues 9 and 10 and in Tables $A-2$ and $A-3$.

The PI projections have two major drawbacks. (1) The NPC methodology adopted is primarily a bookkeeping procedure linearly converting inputs into outputs, and no measure other than gross qualitative inspection is available for judging whether the projection can be reasonably related to the real world. In the words of the PI Natural Gas Task Force itself, "no one really knows how reliable the results are." (2) As seen in Figure 10, the reserve addition rates projected and necessary to achieve the projected production rates are relatively high. In the ACC case, more gas would have to be discovered in 1985 than in the bumper year 1955. This may be overly optimistic, although it can be argued that, if gas prices rise dramatically under deregulation and if supply is responsive to price, then the PI projections would describe the effect on production more accurately than others. Nevertheless, 
for reasons detailed in. Appendix $A$, the PI projections are used in this report.

The National Gas Survey (NGS) projections were made in 1973, when the average wellhead gas price was around 254/Mcf. NGS case II, chosen for this report, is based on the following assumptions. (a) Onshore: the projection for non-associated gas, which forms the bulk of total supply, is based on a hypothetical wellhead price ranging from 34c/MCf in 1975 to 58c/MCf in 1990, and that for associated gas is based on crude oil projections. (b) offshore: development would occur in all three offshore areas, but 5 years behind thẹ current schedule. Note that Alaskan pipeline, and ING imports were also projected by NGS but are not included in this report.

Considering that the average wellhead price has already reached $52 \% / M c f$ in 1975 and is still rising, one could argue that the price assumption on which the forecast of the largest single supply (onshore, non-associated) is based is totally unrealistic and therefore this entire projection should be dismissed.. On the basis of price alone, this would be so: however, as seen in Figure 10, the reserve addition rate necessary to maintain the projected production rate compares quite favorably with the average reserve addition rate since 196n, and its achiovement io probable $17^{\prime}$ ill view of the increase in drilling activities during the past few years. (Drilling activity in 1974 was the highest ${ }^{13}$ since 1956 and is still rising in 1975.). Included in Figure 10 for somparison is the reserve addition rate implied by NGS case I (the lowest of the four NGS projections), which is in the vicinity of the average rate since. 1968.

Note that, for the offshore gas supply at least, it is assumed in all these projections that there would be an adequate number of drilling rigs, necessary equipment, and trained personnel. Wcre 
this not the case, the estimates of future gas supply would be more pessimistic.

A completely different approach was taken in projecting gas production in the year 2000. The fact is that only a finite amount of gas remains to be ultimately discovered, and therefore accelerated production in the near term can only lead to reduced production in the future (and vice versa). How much today's production rate will affect tomorrow's, and when the total gas resource will be completely depleted, depend mainly on how much gas there is altogether.

The estimates of ultimate potential gas supply ${ }^{*}$ that are probably most reliable are those by M.K. "Hubbert ${ }^{21}$ and by the U.S. Geological survey. ${ }^{15}$ The former is 1050 Tcf for the lower 48 states and 150 Tcf for Alaska; the latter is 1158 to 1280 Tcf for the lower 48 states and 77,124 to 180 Tcf for Alaska.

Application of Hubbert's method of predicting gas production rate, which is based on historical facts, to these three sets. of figures gives a range of gas production rates for the year 2000 (see Appendix A). The high result, $17.9 \mathrm{Tcf}$, corresponds to 1280 Tcf for the lower 48 states and 124 TCf for Alaska; the medium result, $15.3 \mathrm{TCf}$, to $1158 \mathrm{Tcf}$ and $124 \mathrm{Tcf}$ for the two areas, respectively, and the low result, $11.8 \mathrm{Tcf}$, to $1050 \mathrm{Tcf}$ and again $124 \mathrm{Tcf}$. The BAU and the ACC production forecasts for 1985 were treated as data in making the year 2000 projection, but the difference between them was so small that it hardly contributes to any significant rate difference in the year 2000. As explained above, almost all the differences between the three production rate results for year 2000 are due to different estimates of ultimate potential supply. The above results are summarized in Table 8 and Figure 11.

* As of the end of 1973, a total of 705 Tcf of gas had been discovered (673 Tcf in the lower 48 states and 32 Tcf in Alaska), of which 455 Tcf had been produced and consumed. 


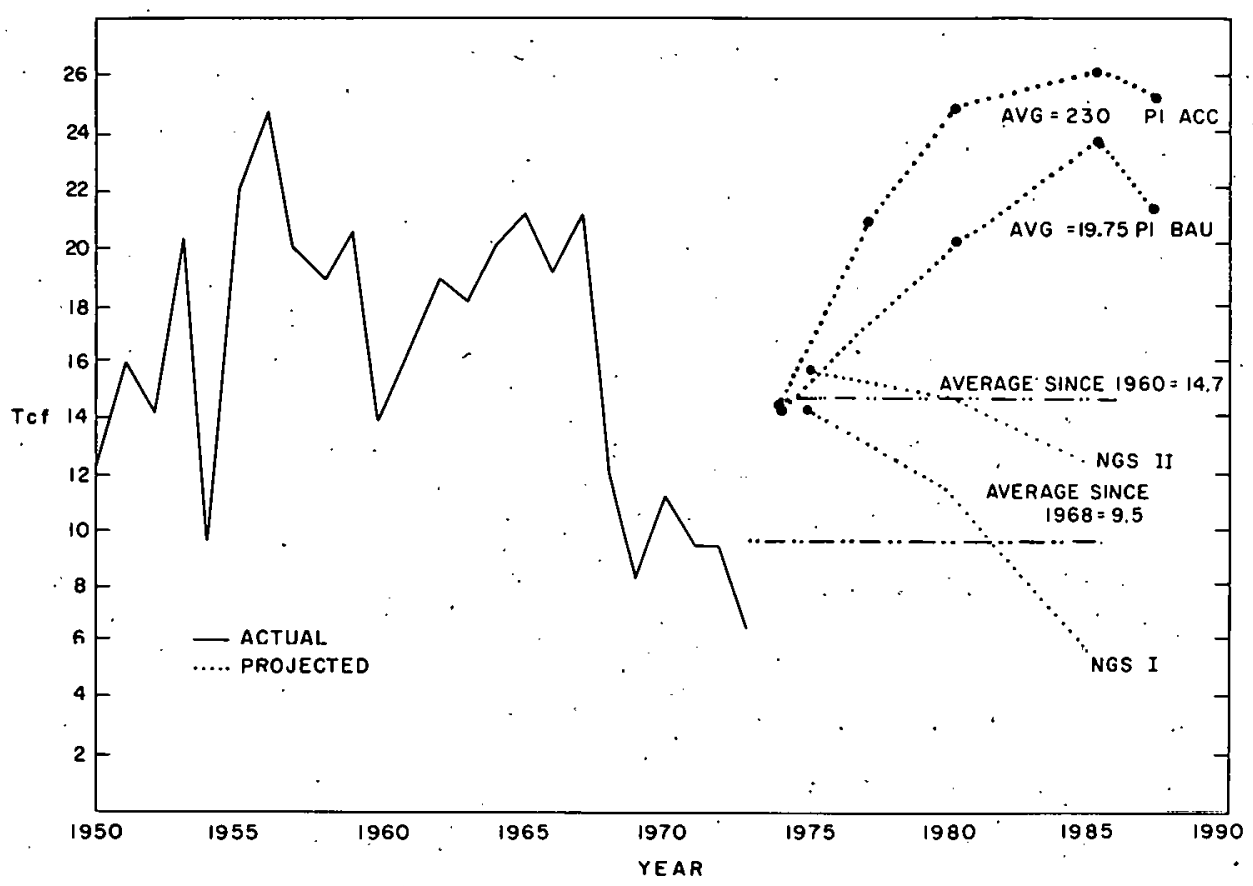

Figure 10. Annual reserve additions, historical and projected.

Table 8

SUMMARY OF NATIONAL NATURAL GAS PRODUCTION PROJECTIONS (TCf) (See Appendix A)

1972. (actua1)

$\underline{1985}$

2000

High

22.8

25.8

17.9

Medium

22.8

22.6

15.3

Low

$22 . \dot{8}$

17.6

11.8

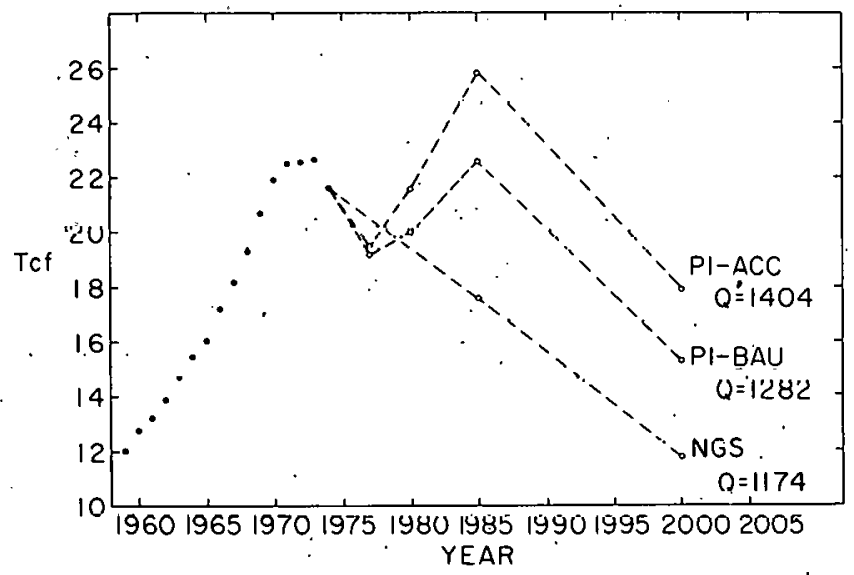

Figure 11. Summary of national gas production projections, 1985 and 2000. 


\section{SOURCES OF GAS WITHIN THE REGION}

As seen in Table 6, onshore production of natural gas within the region (primarily in Pennsylvania) accounts for only a small part of the gas consumed in the Northeast, little more than $3 \%$ in 1972 .

One potentially very important indigenous source of gas, however, is the Atlantic outer continental shelf (OCS). The most recent U.S. Geological Survey estimate ${ }^{15}$ of the amount of gas beneath the Atlantic offshore region is between 0 and 22 Tcf, about two-thirds of it being in the Georges Bank and Baltimore Canyon areas (Figure 12). Several earlier estimates of gas beneath the Atlantic ocs ranged from 35 to 55 Tcf. Few geological data are available on these regions, and no exploratory drilling whatever has yet been

All predictions of gas content and eventual gas production, therefore, necessarily bear a high degree of uncertainty, and this caveat should be kept in mind throughout all considerations of the ocs.

The projections of Georges Bank and Baltimore Canyon gas production for this study were based on the 1974 report to the President on OCS Oil and gas prepared by the Council on Environmental Quality (CEQ). ${ }^{16}$ These projections, 219 Bcf in 1985 and 987 Bcf in 2000 from each area, are averages of the high and low cases in that report; they were calculated with use of the larger gas resource estimate for the OCS, and thus might be considered somewhat optimistic. Nevertheless, the CEQ numbers provide some quantitative basis for estimating the contribution of indigenous gas resources to the region's supply, should such resources exist.

The issue of offshore development is surrounded by controversies of several types. The issues, such as timing and safety of development, economic impacts, etc., 


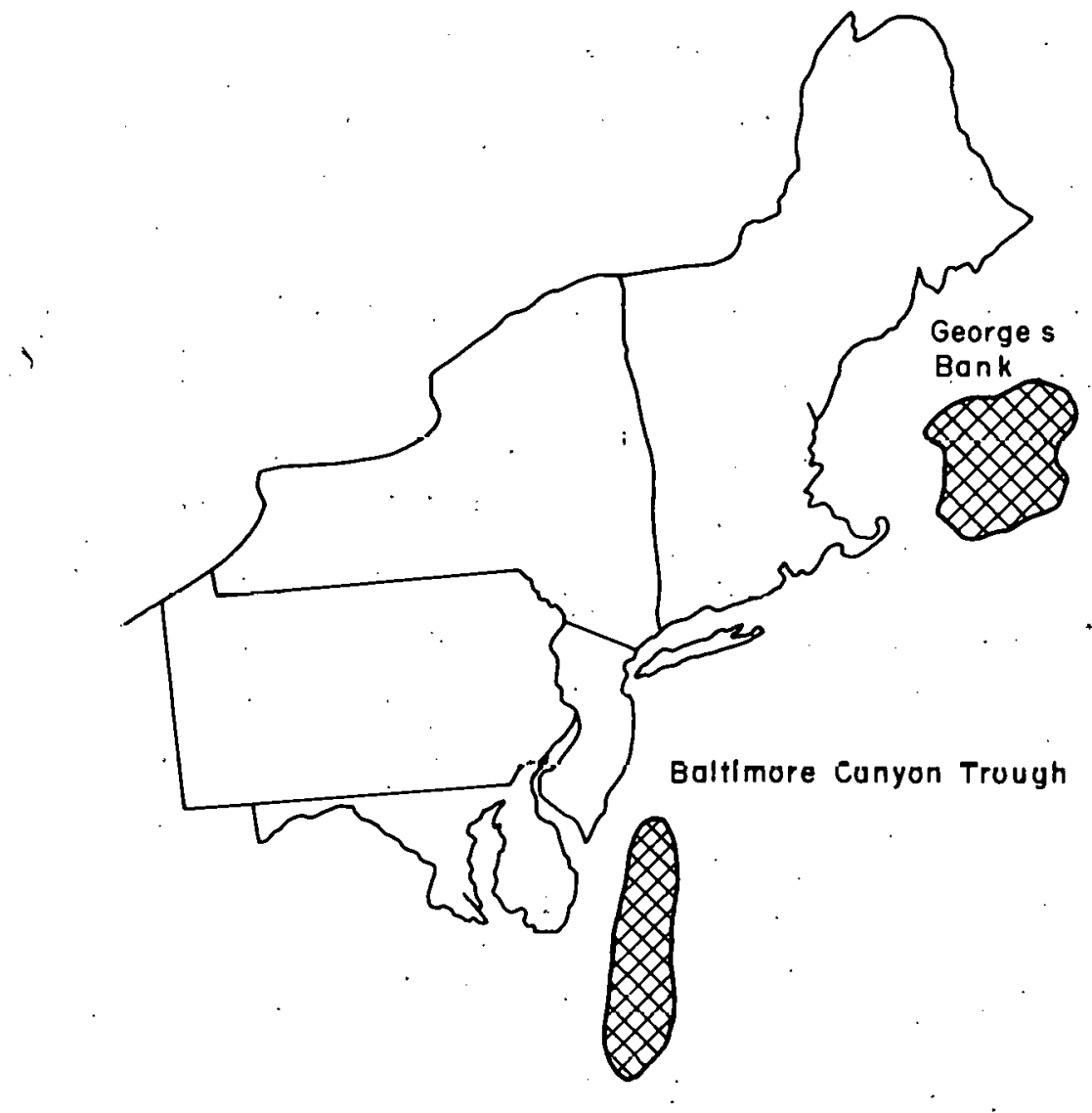

Figure 12. Potential gas-producing areas in the atlantic offshore region: 


\section{SCENARIOS OF NORTHEAST GAS SUPPLY}

National interstate gas and Atlantic ocs gas will be the sources of domestic natural gas supply to the Northeastern United states during the next quarter-centruy. (Imported gas and synthetic gas are considered elsewhere in this study, BNL50556, Supply of Liquified Natural Gas to the Northeast Region.)

Even given some idea of how much of each type of gas will. be available in a given year, one must still decide how the gas will be apportioned among regions of the United states in order to determine the amount coming to the Northeast. Because of the network-like structure of the interstate pipeline system, an analysis of supply distribution requires simultaneous consideration of the demand, price, and transmission factors in force in all of the country's gas markets. Such an analysis would require a highly detailed modeling effort, the results of which would be limited by the uncertainties involved in production and price estimates.

A simpler approach is the scenario method, which is used here; it is based on acknowledging the uncertainties involved but nevertheless using the available supply estimates to set limits on the amount of gas potentially available to the region under different sets of assumptions.

If the ocs region begins producing a substantial amount of gas, and if all this oCs gas is.used within the Northeast, how will the percentage share of interstate gas sent to the region be affected?

Scenario 1:" In the most optimistic case, the region could use all or most of the gas from the OCS and still retain its present share of pipeline gas (if, for example, deregulation allowed the region's interstate suppliers to outbid heavily their 
intrastate rivals for new gas contracts).

Scenario 2: Suppose that the intrastate users of natural gas in the South (primarily Texas, Louisiana, and Oklahoma) never use more than 7.7 Tcf/year, the amount they used in 1972, 19 leaving the remainder of the year's production to enter the interstate system. Then the Northeast would get its historical share of this remainder and would also get most of the gas produced at Georges Bank and Baltimore Canyon.

Scenario 3: This case is the same as scenario 2, except that the interstate share left after the intrastate market cut contains no gas from Alaska in order to show the affect either of no Alaskan development or of all Alaskan gas being absorbed by the West coast.

Each of these three scenarios can be operated with or without inclusion of the ocs production.

Table 9 summarizes the projections of regional supply constructed by using this scenario approach. The high, medium, and low estimates for future interstate-system contributions were based on the high, middle, and low national production extimates. If, by year 2000 Altantic OCS gas is not being produced (either because it does not exist or because it has not yet been discovered and developed), obviously the Northeast would not obtain the 1730 Bcf projected here, and the total amount of domestic natural gas available to the region would range only from 30 to $1740 \mathrm{BCf}$, most likely falling far short of demand. To fill the gap the Northeast would have to switch to other fuels or increase its use of synthetic gas (SNG) or liquified natural gae (LNG):

Figure 13 displays the projections graphically. The estimates for 1977 and 1980 were obtained by applying scenario 1 to the PI ACC estimate for those years and by applying scenario 2 to the PI BAU estimates. The lines connecting the data points are arbitrarily straight to give an indication of trend. 
Table 9

NATURAL GAS SUPPLY TO NORTHEAST (BCF)

1972 (actual)

77.9

Onshore in region

ocs gas ${ }^{b}$

Canada

Interstate:

10.1

$\underline{1985} \cdot \underline{2000}$

$140^{\mathrm{a}}$

$380^{\mathrm{a}}$

$1730^{\mathrm{b}}$

2248 (incl. losses)

2540

1740

2100

1050

Scenario 3. (low)

1360

30

Total

2336

Scenario. 1

3060

3470

Scenario 2

2620

2780

Scenario 3

a Based on the Project Independence BAU estimate for NPC region 10 (Appalachia), reduced by the historical fraction of region 10 gais produced within the Northeastern states considered in this study. This source of gas. is assumed negligible by 2000 .

$\mathrm{b}$

Based on CEQ middle estimate, assuming. all of Georges Bank and three-fourths of Baltimore Canyon gas will go to region.

C

Future gas imports are not a part of the natural gas supply section of this study. Canadian export is a negligible source of gas to the Northeast as a whole. 


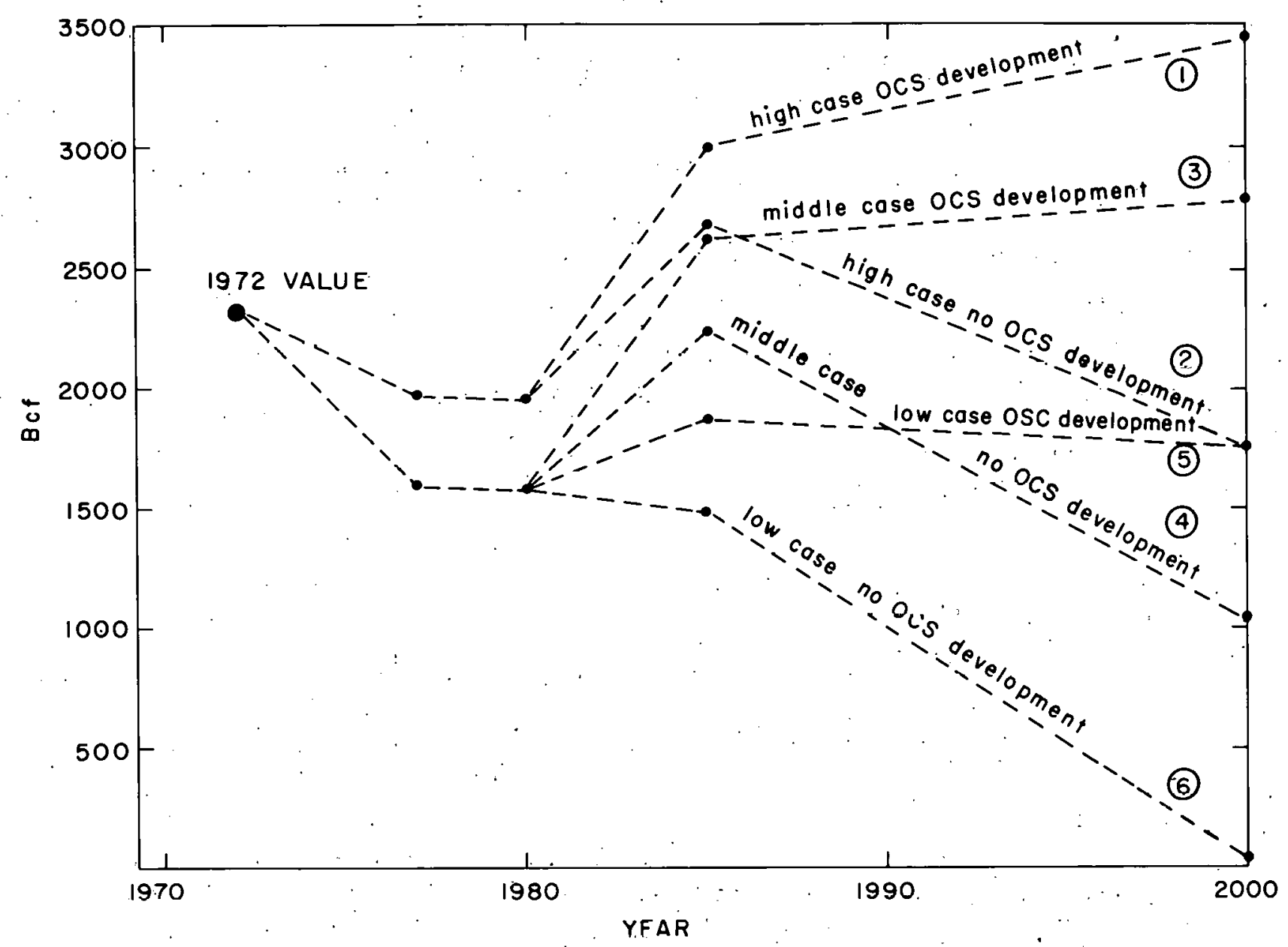

Figure 13. Summary of supply projections for Northeast region. 


\section{SUMMARY}

The amount of natural gas available to the Northeast in the coming years will depend on three things: the amount of gas produced in the United States, the rate of development of nearby outer continental shelf gas, and the distribution of gas from both these sources among the states. The factors that will influence these three variables are more difficult to assess; politics will be important, as well as economics, geology, and technology.

In this report state-of-the-art estimates have been provided for national and local OCS gas supplies in 1985 and 2000, and the estimates have been coupled with a schematized set of possible apportionments. This approach is helpful in the consideration of the political and economic aspects of gas distribution because it shows clearly the upper and lower bounds and gives some idea of the differential effects of various policy options (such as ocs dèvelopment) .

This report also provides background information on the gas situation in the Northeast region, including the types of use, which may provide useful insights into the effects of possible national and state policies. For example, since the wellhead. price of yas is only a small part of the price paid for gas in the Northeast, deregulation (which could triple the wellhead price) would be expected to have less effect in this region than elsewhere; indeed, since the region must now use expensive synthetic gas to make up for the short interstato oupply, dereyulation, because it would increase the interstate supply, might not raise gas prices at all in some areas. 
Other policies that have been contemplated at the national. level include an end-use tax to discourage the use of gas for putatively low-priority ends and direct imposition of an end use curtailment plan on all gas utilities. Because of the end use mix characteristic of the Northeast (heavily weighted toward high-priority residential and commercial uses), these plans would likely affect this part of the country less than other parts such as the producing states on the Gulf coast. Such plans would benefit the Northeast by rewarding the types of end uses common here while taxing or curtailing the types common. elsewhere, thus f̈reeing more gas for use here. 


\section{APPENDIX A}

\section{VARIOUS PROJECTIONS OF NATURAL GAS SUPPLY}

\section{Introduction}

The natural gas resource system in the United states differs in two notable ways from the oil and coal supply industries. Unlike oil, natural gas cannot easily be shipped in from overseas (with present facilities) to augment deficient domestic production. Furthermore, the present downturn in gas production (and concomitant shortages) points to the limits of natural gas supply -- a situation markedly different from that of the coall industry, which is experiencing and anticipating increases in production, 24 and whose resource base is, by all pronouncements, extensive.

In generating national production projections for natural gas, then, one is dealing with a system that is almost entirely isolatable from external supply inputs and is governed, at least in the long run, by constraints of supply rather than by consumer demand. These rather unsubtle observations make a useful starting point for the development of national projections. The question of how to proceed from this starting point has, however, no straightforward answer. Projection is, fundamentally, the technique of extrapolating forward in time the operation of a highly complex system. The amount of natural gas produced and sold in any year is an impossibly complex function of economic, political, and technical variables; to reduce this function to tractable form, onc creates models that idealize the function into analogous systems of varying degrees of complexity. 
The problem is exacerbated somewhat when one is attempting to project as far as a quarter-century into the future; in general, the very detailed models adapted to near-term projection lose validity in the more distant future, and simplified models useful in long-range estimation normally neglect short term fluctuations.

The purpose of this report is to demonstrate that one can attack the problem with the available set of models and, by making some. straightforward assumptions about the natural gas resource system, develop a realistic, up-to-date, and selfconsistent.set of projections for 1985 and 2000 -- projections that enjoy the benefits of complex modeling where useful and yet are based on verr. simple and fundamental reasoning.

\section{Resource Projection Methodologies}

The extant methods of mathematical resource projection can be ordered on a spectrum ranging from econometric analysis to approaches of the logistic equation type. The former method deals explicitly with selected economic variables affecting production: one calculates the necessary parameters by fitting historic data, and then extrapnlates forward. As the published literature amply demonstrates, this lype uf andyois often ignores the constraints imposed by the ultimately recoverable resource base or by technical limitatioñs on annual production. And even the most careful of these forecasts have little validity beyond, at best, a decade and. à halr iulo the future, at. which point the error bars on the economic parameters begin to grow rapidly with time. 
Figure 8 showed some of the most prominent recent projections. Those by MacAvoy and Pindyck 25,26 and by Hudson and Jorgenson $^{27}$ are econometric. The former, for example, uses linear least-squares fit to historic data for a myriad of parameters, describing such quantities as prices of gas, prices of oil, numbers of wells drilled, drilling risks, cash flows, sizes of new discoveries, etc.

Hubbert's Analysis

The Gaussian shapes in Figure 8 are logistic curves, often called Hubbert ${ }^{21.28}$ curves. Unlike their econometric counterparts, the Hubbert curves are derived from a least-squares. fit of only two arbitrary constants. Since this method plays a role in the analysis used for this study, it is instructive to examine the logistic equation technique in some detail.

One begins, in this approach, with the assumption that the cumulative production of a resource throughout its history can reasonabiy be described by the following equation:

$$
Q_{e}=Q_{\infty} /\left(1+a e^{-b t}\right)
$$

where $Q_{e}$, the cumulative production, is the total amount of the resource removed from the ground since the beginning of time; $Q_{\infty}$ is the amount ultimately recoverable; $t$ is time (with an arbitrary zero point); and $a$ and $b$ are constants to be determined, by means of linear regression, from historical data. (Rearranging the equation and taking logs, one finds that

$$
\left.\ln \left[Q_{\infty} / Q_{e}\right)-1\right]=\ln a-b t
$$

which implies that solution for a and b is easy by using linear regression on historic values of $Q_{e}$ for a given $Q_{\infty}{ }$ ) 
The expression for $Q_{e}$ is, first of all, doubly asymtotic, resting at zero for $t=-\infty$ and bounded by $Q_{\infty}$ for $t=+\infty$. Qualitatively, this is the asymtotic behavior one would demand of a model of resource utilization. Figure A-1 illustrates the behavior of $Q_{e}$ in more detail: During the early history of the resource, the exponential term dominates, giving an exponential rise in production. Later, as that term approaches a value of one, the progression in cumulative production becomes nearly linear, and the slope begins gently to turn over. It is here that the slope is steepest, i.e.. the rate of production is greatest. As the resource becomes dcploted, the exponential, term approaches zero and $Q_{e}$ approaches $Q_{\infty}$.

The exact shape of the curve is governed by the values of $a$ and b. But in this form, the curve is nearly symmetric around the point of peak production and so is its derivative, the annual production:

$$
d Q e^{/ d t}=a b Q_{\infty} e^{-b t} /\left(I+a e^{-b t}\right)^{2}=a b Q e^{-b t} /\left(1+a e^{-b t}\right) .
$$

One can, however, introduce a parameter $s$, for skew, to distort the shape of the curves without changing their general properties:

$$
Q_{e}=Q_{\infty} /\left(1+a e^{-b t}\right)^{s}, \quad: d Q_{e} / d t=s a b Q_{\infty} e^{-b t} /\left(1 \% a c^{-b t}\right)^{s+1} .
$$




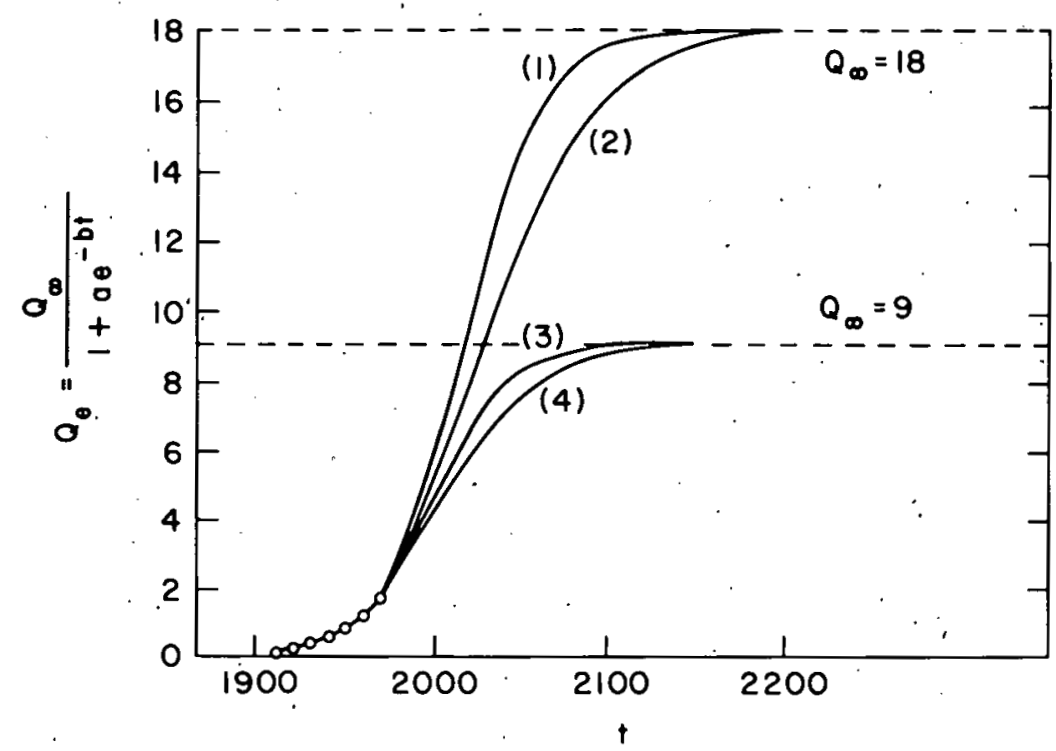

Fígure A-1. Typical logistic curves of cumulative production.

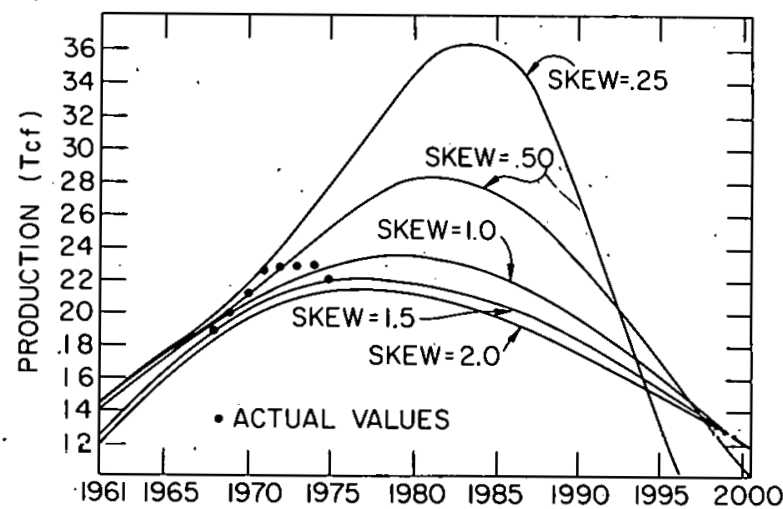

Figure A-2. The effect of skew on a Hubbert curve for fixed $Q^{\infty}$. 
From a given $Q_{\infty}$ and historical data on $Q_{e}$, constants a and b can again be determined, by means of linear regression, for any given s. However, $a$ and $b$ so determined.will be different for different values of .s.

Figure $A-2$ shows the effect of skew on the annual production rate. Each curve represents the rate for a given skew and its corresponding $a$ and $b$, that is, not only skew, but also $a$ and $b$ vary from curve to curve. An exponent of unity produces the most nearly symmetric curve; exponents < 1 tend to sharpen the peak while diminishing rates of future production; and exponents $>1$ tend to smooth the cusve's peak whilc insroasing future production.

The central argument against the logistic curve approach is that it is essentially a physically based model (its most important parameter being the physical quantity $Q_{\infty}$ ' that does not deal explicitly with the economics of the resource. Proponents of the method argue that this subsumption constitutes a reasonable and accurate treatment of the economics; opponents argue that the economics should be included more explicitly in any model. Indeed, active debate continues regarding the validity of Hubbert's analysis (although most of the controversy addresses the use of logistic curves as predictors of $Q_{\infty}^{\prime}$ rather than as projectora from an assumed $\left.Q_{\infty}\right) .^{29}$ It is not the intention here to enter the debate, but some justification for the use of logistic curves in this report is in order.

From a historical perspective, one can safely argue that at $t=-\infty$ and $t=+\infty$ the annual consumption of a resource is zero: all consumption has occurred in between. Thus the annual production curve must be fixed at zero at the infinities. Furthermorc, the total amount consumed, i.e., the integral over time of annual consumption, must approximate the amount of the resource in the ground (or, more precisely, the amount that was considered to be 
economically removable from the ground).

From this point of view, one can imagine the annual production curve as a draftsman's spline clamped to a table-top at both ends and allowed to bulge up in the middle. The bulge represents $Q_{\infty}$ ' the area under the annual production curve. With its ends clamped, the spline can be made to assume any desired shape without changing the area of the bulge. A Hubbert curve can be thought of as a convenient mathematical representation of such a spline; and this particular mathematical form was chosen because it provided the best fit to the historical data of all the curves Hubbert considered.

The central advantage of the Hubbert curye (aside from simplicity) is that it predicts the total amount of a resource. Despite the debate, the total resource base is what must be, considered in carrying out projections. As Figure 8 showed, the logistic curves serve as a handy visual quide to what overall production rate is allowed and make it easy to tell what value of $Q_{\infty}$ is implied by the curve of a particular projection. Production rate curves with nonunity skew also retain this feature, permitting easy assessment of the future effect of an accelerated near-term rate and, conversely, of the long-term effect of a currently reduced rate.

Overview of Published Projections

The projections in Figure 8 are a mixed lot, obtained by both econometric and more physically based methods. Of the MacAvoy-Pindyck and Hudson-Jorgenson projections which are econometric, the former appear to be unjustifiably sanquine and the latter, in comparison with the Hubbert curves, is difficull to believe at the year 2000 . 
Other projections, specifically those of the FEA's project Independence (PI), ${ }^{30}$ the FPC's National Gas Survey (NGS), 31 and the National Petroleum Council (NPC), ${ }^{32}$ are primarily physically based models. Unlike the Hubbert analysis (which might be described as a simplified or nondetailed physical analysis), these projections model physical variables in a comparatively detailed way. They do not, however, use price or cost variables in the formulation of the production projection. Rather, price calculations (in the PI and NPC cases) become afterthoughts, con strucled on the basjs of assumptions about production costs and rates of return on ilvestmenta, and are intended only to indicate the level of economic activity implied by the physical results calculated.

The most important of. the physical inputs are the projected drilling rates (numbers of feet drilled per year) and the finding rates (amounts of gas reserves added per foot drilled). (See Table A-1.) The general approach is to construct a projection for drilling activity, to calculate values for finding rates from either historic data or geological information, and then to formulate yearly production on the basis of yearly adaitions to reserves.

Tn the NGS ${ }^{14,31,33}$ method the country is aisaggregated into geological regions (standard NPC regions). Gas sources are then classified according to "vintage" (year of discovery), and a "national availability curve" (a functional relation between annual proturtive capability and the depletion state of the gas source, drawn from industry-supplied deliverability data) is used to compule annila 1. production.

The NPC ${ }^{32}$ methodology is similar: it postulates sceriarios ful drilling and finding rates (by geographical region) and uses a schedule of factors to relate yearly reserve aditions in cach region of production rates. Once the prodiction scenarios have been established, the average gas price is calulated which would provide 
Table A-1

GAS DRILLING ESCALATION FACTORS AND PROJECTED GAS WELL FOOTAGE 30

\begin{tabular}{llccc} 
& \multicolumn{2}{c}{ Percent annual increase } & & Gas well footage* $\left(10^{6} \mathrm{ft}\right)$ \\
Year & BAU & Accelerated & BAU & Accelerated \\
1974 & 0.0 & 0.0 & 59.7 & 59.7 \\
1975 & 5.0 & 8.3 & 62.6 & 64.6 \\
1976 & 5.5 & 15.4 & 66.1 & 74.6 \\
1977 & 6.0 & 13.3 & 70.1 & 84.5 \\
1978 & 6.5 & 11.8 & 74.6 & 94.5 \\
1979 & 7.0 & 5.3 & 79.8 & 99.5 \\
1980 & 7.5 & 5.0 & 85.8 & 104.4 \\
1981 & 8.0 & 4.8 & 92.7 & 109.4 \\
1982 & 8.5 & 4.5 & 100.6 & 114.4 \\
1983 & 9.0 & 4.3 & 110.6 & 119.3 \\
1984 & 7.0 & 4.2 & 117.3 & 124.3 \\
1985 & 5.0 & 4.0 & 123.2 & 129.3 \\
1986 & 3.0 & 3.9 & 126.9 & 134.3 \\
1987 & 1.0 & 3.7 & 128.1 & -139.3 \\
1988 & 0.0 & 3.6 & 128.1 & 144.3
\end{tabular}

* Includes allocated dry hole footage.

a given rate of return on the total investment needed to achieve the various production levels.

The. Institute of Gas Technology (IGT) ${ }^{34.35}$ model deals explicitly with annual production, cumulative prodictinn, and cumulalive discoveries as variables; it relates these, in two equations like Hujbert's equation, to several empirically (historically) fitted parameters. The IGT cases in Figure 8 were calculated by a "fixed static life-index" method, in which annual production values were regulated in such a way that, for any year, the proven reserves divided by the annual production 
never exceeded a given value, in this case, eight. The reserves-toproduction (R/P) ratio; also called the static life-index, gives the number of years proved reserves would last at a given rate of production. It is often desirable to keep the $R / P$ ratio at a minimum as a way of acknowledging that production has physical limitations (notably a decrease in reservoir pressure) as the working resource base becomes depleted. This set of IGT projections also involved an "economic incentive factor," defined as the ratio of the weighted average wellhead price of oil and gas divided by the square of the average well cost. This factor was histurically determined and inserted into the equations in an appropriate way, making the model vaguely econometric. The IGT curves in Figure 8 assume a $Q$ of 1447 Tcf.

The Project Independence ${ }^{30}$ projections were made by the NPC, method. The FEA Natural Gas Task Force did, however, modify the economic aspect of the NPC algorithm, inserting a system to calculate "minimum acceptible prices" by using a discounted cash flow technique. The net effect is similar to the economics of the NPC report.

Discriminations Among the Projections

As Figurc 8 demonstrates, the set of projections considered offers a predictive range comparable in scope to that of the Delphic oracle. Clearly, one must distinguish among them. The case against the econometric forcasts has already been discussed. The IGT projections might also be eliminated because their wide range limits their operational usefulness, and, more signigicantly, the curves are manifestly unable to follow the trend presented by the 1972 through 1975 data, even though they were obtained from a report dated 1974: Of the remaining projections, the most recent are from Project Independence, which was completed between Aprị 
and October; 1974. The NPC projections use data through 1971, whereas Project Independence had the benefit of 1973 data.

The NPC and NGS curves are reasonably congruent both in trend and in spread of possibilities. Project Independence, in contrast to the general trend of the forecasters, shows a continuation of the present downward movement. for the next few years followed by an upswing. If 1975 gas production continues at the rate implied by first-quarter figures, production this year will be 10\% less than last year, almost exactly the prediction of the PI curves. Furthermore, the qualitative behavior of the PI projections is reasonable if one admits the validity of the view expressed by FPC and industry that the present slump is due to government price controls, which keep the market value of gas artifically below that of alternative fuels. According to this view, if prices were raised and/or controls were lifted, the industry would respond with increased drilling and eventually increased production.

The national average wellhead price of natural gas is now $51 \%$ per thousand cubic feet, ${ }^{36}$ almost twice the $27 \%$ in force until 1973, and an increase over the 42\% level set in early 1974. 37 At present, several natural gas bills are before congress; their terms range from complete (though "phased") decontrol to restriction of gas prices to the equivalent price of oil (514 corresponds to about $\$ 3$ per barrel). 8 The prospects for increased,incentives are thus good.

Another argument in support of the possibility of a production upswing is the Hubbert curve: continuation of the present trend obviously. would imply an ultimate cumulative production far below even the llust conservative estimate of $Q_{\infty} \cdot$ (This means that the resource base obtainable with present economics in force is less than that predicted by the logistic curves, which are computed 
from historic production levels representative of a more favorable past economic climate, i.e., a return to those putatively more favorable conditions could result in more gas.)

Since the PI projections are (1) recent, (2) accurately predictive of 1975 behavior, and (3) qualitatively reasonable, they are useful base-case and upper limit projections for 1985 . These projections are summarized in Table A-2 for the lower 48 states by NPC regions; they correspond to a $\$ 2 /$ Mcf price. Since the present slope of the production rate curve is, nevertheless.. drastically negative, it would seem sensible to include the possibility that. this trend will not change completely and therefore to consider a more conservative lower limit. This is illustrated in Figure 10. The two lower scenarios for yearly reserve additions correspond to NGS cases I and II. The average of yearly additions since 1968 is 9.5 TCF; gince 1960. it is 14.7. Because there do seem to be potential increases in incentives for drilling (as well as preliminary indications that drilling has in fact increased), ${ }^{38}$ case II, a return to the $1960-73$ average, seems a reasonable lower limit. Furthermore, Figure 8 indicates that in 1985 NGS Case II closely approaches the analogous NPC prediction.

Extending the 1985 Projections

The Hubbert analysis can be used to extend these 1985 projections to 2000 by including as data not only actual historic figures but also the various projections. This allows the Hubbert curve, obtained bỳ means of leagt--cquares fit, to approximate the trend. implied by the projection. Next, the skew parameter is adjusted to force the curve to pass through the 1985 value of the projection in question. This gives an indication of the effect at 2000, for a given resource base, of near-term production according to the 1985 
TABLE A - 2

PROJECT INDEPENDENCE SUMMARY OF MARKETED NATURAL GAS PRODUCT ION, *

LOWER 48 STATES (TCF)

B!isiness As Usual

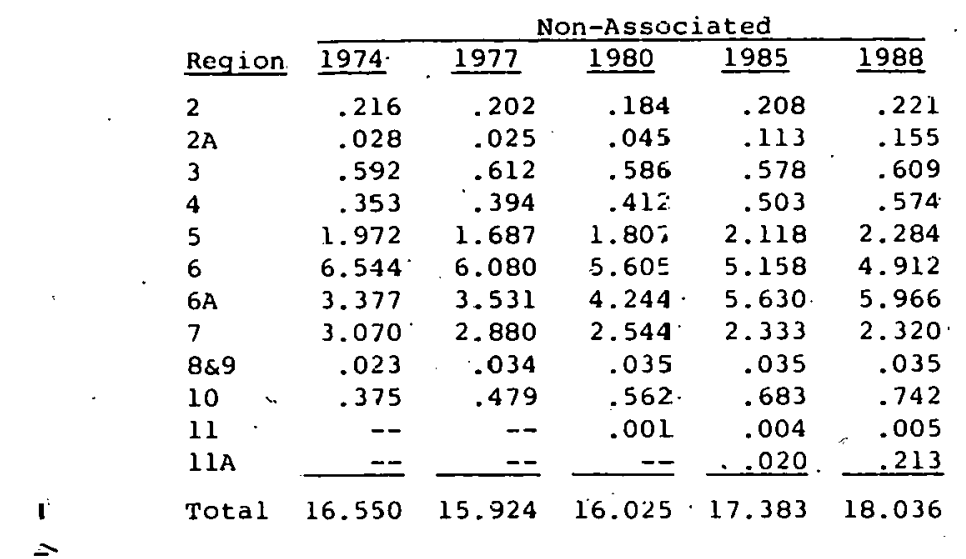

\begin{tabular}{|c|c|c|c|c|c|c|c|c|c|}
\hline \multicolumn{5}{|c|}{ Associated-Dissclved } & \multicolumn{5}{|c|}{ Total } \\
\hline 1974 & 1977 & 1980 & 1985 & 1988 & 1974 & 1977 & $\underline{1980}$ & 1985 & 1988 \\
\hline .163 & .138 & .126 & .119 & .102 & .379 & .340 & .310 & .327 & .323 \\
\hline .013 & .020 & .054 & .137 & $1 \div 0$ & .041 & .045 & .099 & .250 & .345 \\
\hline .041 & $.040^{\circ}$ & .039 & .041 & .043 & .633 & .652 & .625 & .619 & .652 \\
\hline .162 & .146 & .143 & .150 & .153 & 515 & .540 & .555 & .653 & .727 \\
\hline 1.014 & .811 & .667 & .485 & .352 & 2.986 & 2.498 & 2.474 & 2.603 & 2.636 \\
\hline 1.198 & 1.004 & .935 & 1.058 & 1.178 & 7.742 & 7.084 & $6 . \dot{5} 40$ & 6.216 & 6.090 \\
\hline .521 & .513 & .567 & .703 & $: 756$ & 3.698 & 4.044 & 4.811 & 6.333 & 6.722 \\
\hline .513 & .420 & .329 & .188 & .095 & 3.583 & 3.300 & 2.873 & 2.521 & 2.415 \\
\hline - & -- & -- & -- & -- & .023 & .034 & .035 & .035 & .035 \\
\hline .024 & .023. & .025 & .032 & .036 & 399 & .502 & .587 & .715 & .778 \\
\hline .001 & .001 & .002 & .007 & .011 & .001 & .001 & .003 & .011 & .016 \\
\hline$=$ & $=-$ & $-=$ & .009 & .023 & $=-$ & - & - & .029 & $\therefore .236$ \\
\hline 3.650 & 3.116 & 2.887 & 2.929 & 2.939 & .200 & 19.040 & 18.912 & 20.312 & 0.975 \\
\hline
\end{tabular}

Accelerated Development

\begin{tabular}{|c|c|c|c|c|c|c|c|c|c|c|c|c|c|c|c|}
\hline \multirow[b]{2}{*}{ Region } & \multicolumn{5}{|c|}{ Non-Ássociated } & \multicolumn{5}{|c|}{ Associated Dissolved } & \multicolumn{4}{|c|}{ Total } & \multirow{2}{*}{988} \\
\hline & 1974 & 1937 & 1980 & 1985 & 1988 & 1974 & 1977 & 1980 & 1985 & 1988 & 1974 & 1977 & 1980 & $\underline{1985}$ & \\
\hline 2 & .216 & .203 & .195 & .225 & .238 & .163 & .138 & .126 & .119 & $.101^{\circ}$ & .379 & .341 & .321 &. .344 & .339 \\
\hline $2 \mathrm{~A}$ & .028 & .031 & .091 & .251 & .345 & .013 & .033 & .114 & .296 & .404 & .041 & .064 & .205 & .547 & .749 \\
\hline 3 & .592 & .615 & .608 & .614 & .640 & .041 & .040 & .039 & .040 & .043 & .633 & .655 & .647 & .654 & . 683 \\
\hline 4 & .353 & .398 & .437 & .540 & .600 & & .146 & .142 & .149 & .152 & .5 & & .579 & $.689^{\circ}$ & .752 \\
\hline 5 & 1.972 & 1.704 & 1.931 & $2.26 i$ & 2.3 & .014 & .810 & .666 & .484 & .351 & 2.986 & 2.5 & 2.597 & 2.745 & 2.707 \\
\hline 6 & 544 & 6.116 & $5: 856$ & 5.449 & 5.066 & 1.198 & 1.001 & .930 & 1.052 & $1: 172$ & 7.742 & 7.1 & 6.786 & 6.501. & 6.238 \\
\hline $6 \mathrm{~A}$ & 3.377 & 3.560 & 4.635 & 6.388 & 6.717 & .521 & .561 & .653 & .811 & .858 & 3.898 & 4.1 & 5.288 & $7: 19.9$ & 7.575 \\
\hline 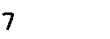 & 3.070 & 2.394 & 2.642 & 2.464 & 2.413 & .513 & .418 & .328 & .186 & .094 & 3.583 & 3.312 & 2.970 & 2.650 & 2.507 \\
\hline $8 \& 9$ & $.023^{\circ}$ & .034 & .037 & .038 & .038 & -- & -- & -- & -- & -- & .023 & .0 & .0 & .038 & .038 \\
\hline 10 & .375 & .486 & .607 & .739 & .7 & .024 & .023 & .025 & .032 & .036 & 399 & .5 & .632 & .771 & .817 \\
\hline 11 & -- & -- & $: 001$ & .004 & .0 & .00 & .001 & .002 & .007 & .011 & .001 & .001 & .003 & .011 & .017 \\
\hline $11 \mathrm{~A}$ & $=$ & $=$ & $=$ & .168 & .509 & - & - & -- & .121 & .173 & $=$ & $=$ & - & .289 & .682 \\
\hline Tota 1 & 550 & 16.041 & 17.040 & 9.141 & 9.709 & 3.650 & 3.171 & 3.025 & 3.297 & 3.395 & 20.200 & 19.212 & 0.065 & 2.438 & 23.104 \\
\hline
\end{tabular}

* Represents all gas produced excluding gas used for reservoir pressure mainteriance and gas used for field use. Non-associated gas production has been reduc: ad approximately 6 percent and associated-dissolved gas producticn has been reduced approximately 13 percent to reflect the hiscorical rate of gas lease use, fuel use and losses. 
scenarios. Figures $A-3$ and $A-4$ illustrate this procedure for the PI BAU and ACC cases.

For best results, production in the lower 48 states should be considered separately from Alaskan production. The lower 48 states are not an optimum system for Hubbert analysis, since it is necessary to include the unknown offshore domains of the East and West.Coasts, but this system is still preferable to one including Alaska, where the uncertainties are inherently even greater.

Projections are avilable for Alaska separately, as are recource estimates. Here again the projections are used as data points (in the PI projections shown in Table A-3, only the 1974 figures are actual), and, for different Alaskan values of $Q_{\infty}$ ' the skew parameter is adjusted. For Alaska, however, the skew adjustment optimizes qualitative fit to the 1975-1985 projections, and it also produces an approximate minimum in mean and root-mean-square fitting error. Figures $A-5$ and $A-6$ show some typical results.

For the lower 48 states, the data used were values of net production, which is defined as all the gas removed frum the ground minus the gas reinjected to maintain reservoir pressure. This differs from marketed productiun by the amount of gas lust in transmission or for other reasons. The net figure is preferable, since the ultimate resource base is independent of whether the gas withdrawn is used or lost. Values of marketed production predicted from the Hubbert curves have been reduced from net values by $6.5 \%$, a weighted average of historic Loss f1gures [ن both oil-associated and non-dssuciated gac. Given the uncertainties in Alaskan prediction, the distinction between net and makster. seems superfluous and was not made. 


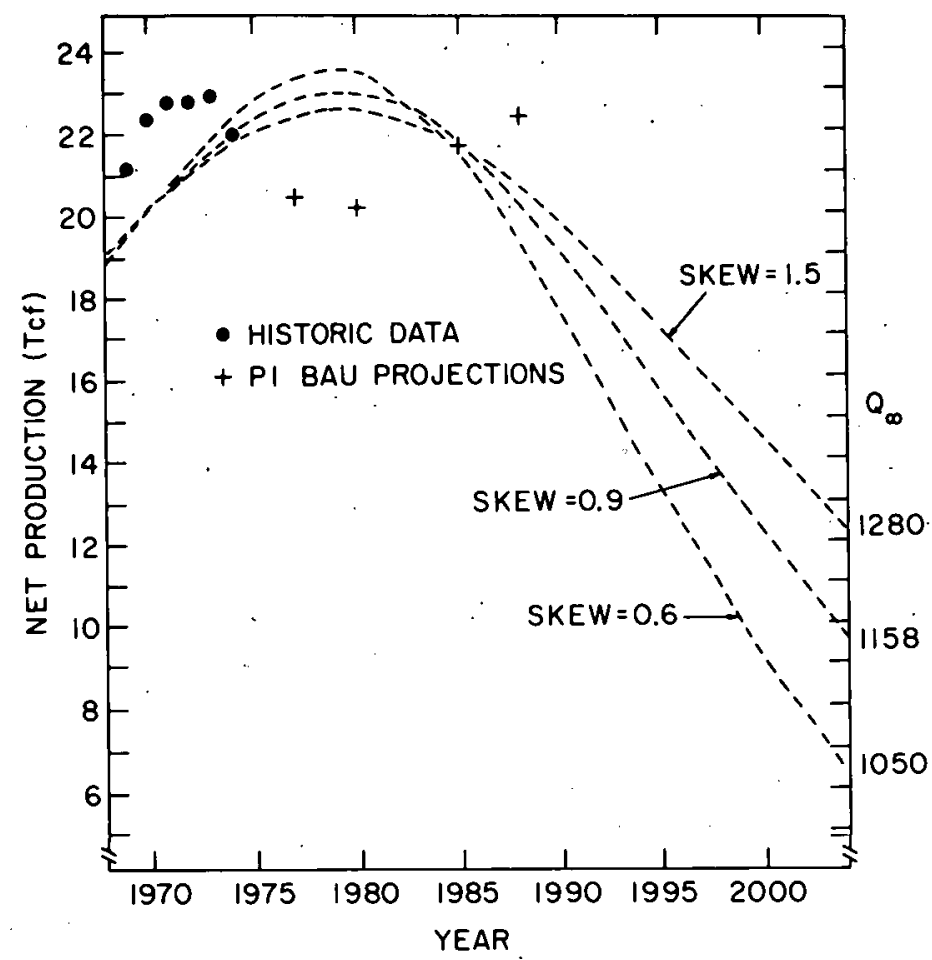

Figure A-3. Hubbert curves, with PI BAU projections as data, skewed to pass through PI 1985 projections.

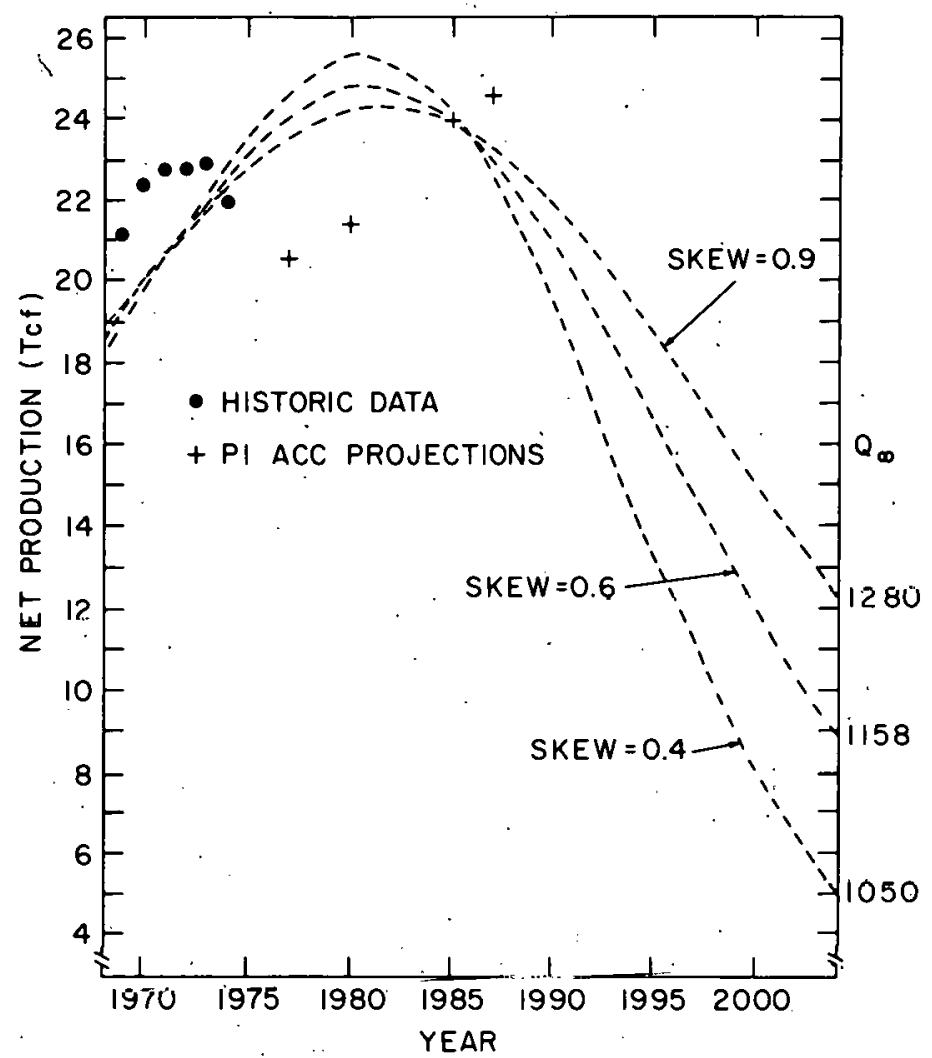

Figure A-4. Hubbert curves, with PI ACC projections as data, skewed to pass through PI 1985 projections. 


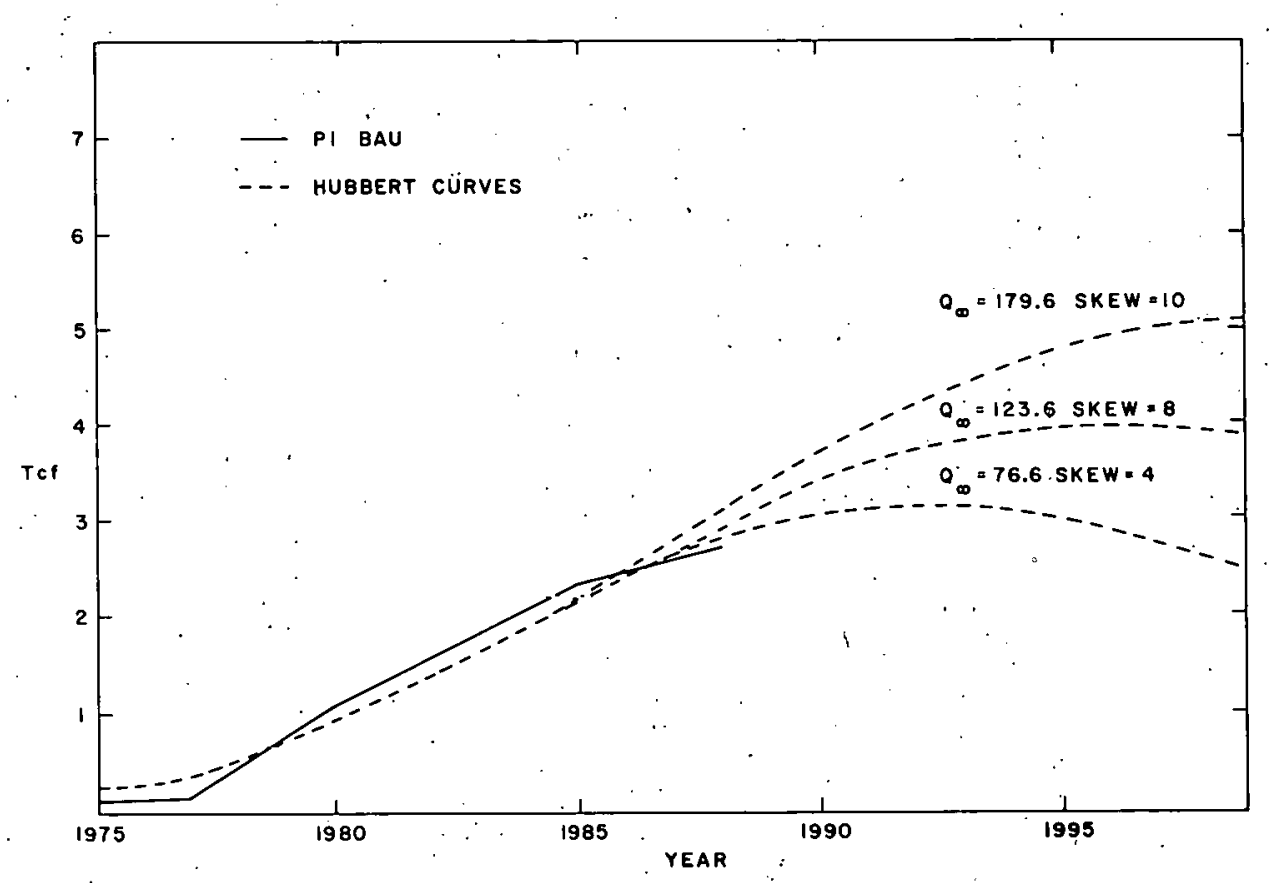

Figure A-5. Use of Hubbert curves to extend PI BAU Alaskan production projection.

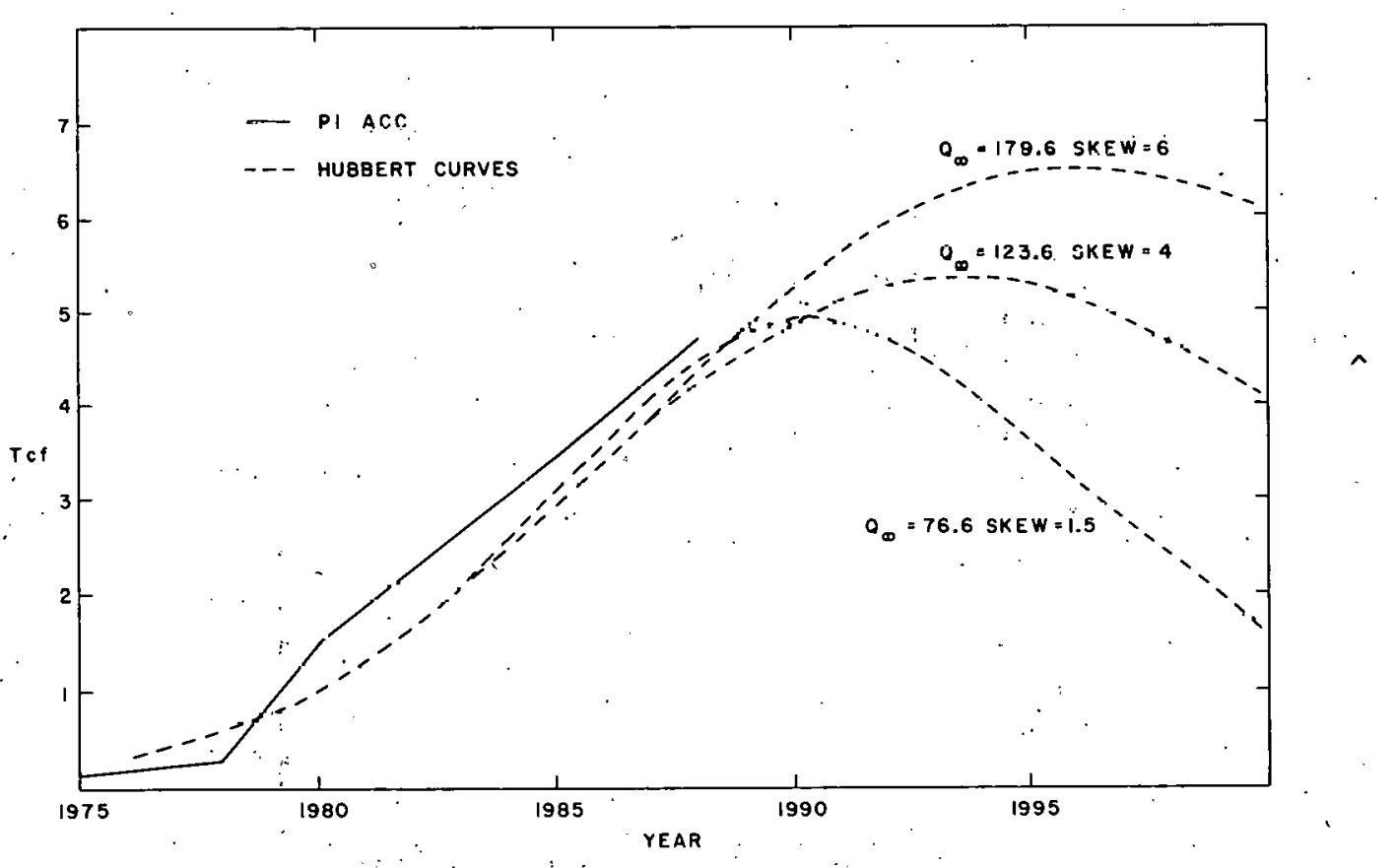

Figure A-6. Use of hubbert curves to extend

PI ACC Alaskan production projection. 
Table $A-3$

\begin{tabular}{|c|c|c|c|c|c|c|c|c|}
\hline PRC & JECTED & MARKETED & GAS & PRODUCTION & SUMMARY, & ALASKA & 30. & $(B \subset f)$ \\
\hline Year & $\cdots$ & & & BAU * & $\therefore \quad \therefore$ & & & $A C C^{*}$ \\
\hline - & & & & Non-associat & ted & & $\because^{\circ}$ & \\
\hline $1974^{\circ}$ & & & & 11.5 & $\because$ & & & 115 \\
\hline 1977 & & . & & 140 & . & & & 260 \\
\hline 1980 & & & & 380 & & & & 745 \\
\hline 1985 & & & & 915 & $\ldots \quad \ldots$ & & & 1675 \\
\hline 1988 & & & & $\quad 1255$ & & & & 2280 \\
\hline & & & Ass & sociated-Dis & ssolved** & & & '. \\
\hline 1.974 & & & & 15 & & $\therefore$ & : & 15 \\
\hline 1977 & $\therefore$ & & & i7 &. & . & . & 19 \\
\hline 1980 & & & & 700 & & & & 780 \\
\hline 1985 & & & & 1410 & & $\cdot \cdot$ & & 1770 \\
\hline 1988 & & & & 1445 & & & & 2444 \\
\hline & . & & & Total & & & & \\
\hline 1974 & & & & 130 & & & & 130 \\
\hline 1977 & & ' & & 157 & & & & 279 \\
\hline 1980 & ${ }^{\circ}$ & . & & 1080 & & & & 1525 \\
\hline 1985 & & & & 2325 & & & & 3445 \\
\hline 1.988 & . & . & & 27.00 & & . & & 47.24 \\
\hline
\end{tabular}

* High cases only.

** Includes associated-dissolved gas production projections for South Alaska made by the Oil Task Force.

Table $A-4$

SUMMARY OF PROJECTIONS FOR HIGH (ACC) AND MEDIUM (BAU) CASES (TCF) (Projection for low case (NGS rase II) not sliuwn)

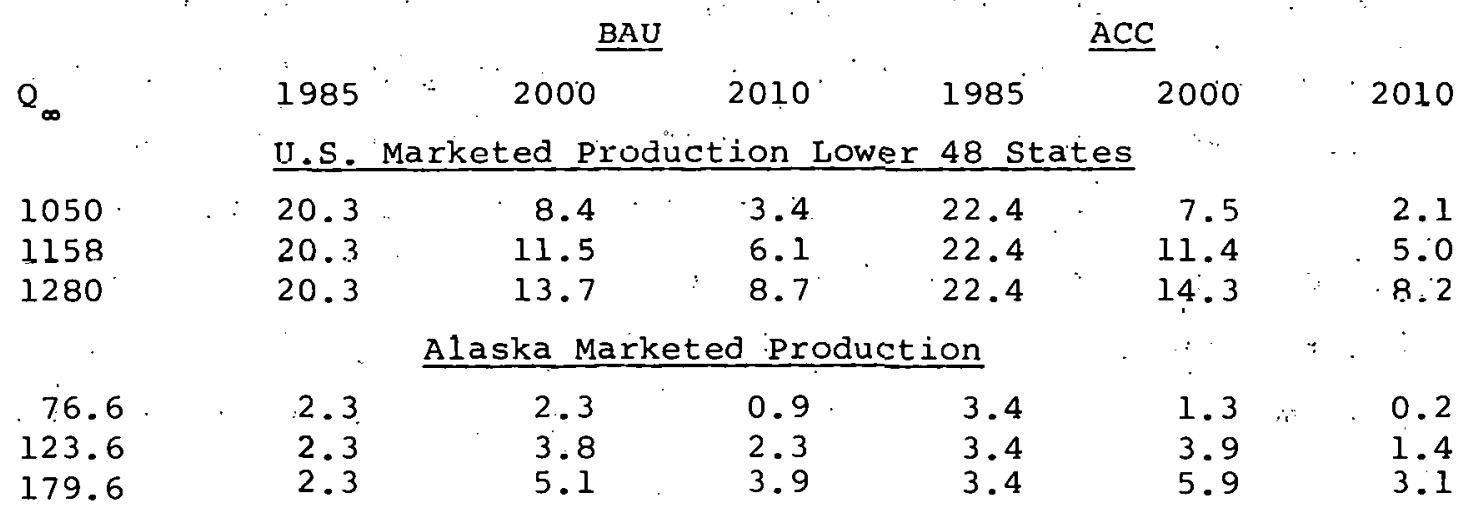


Since this type of analysis is sensitive to the value of $Q_{\infty}$, care should be exercised in selecting an ultimate resource figure. Much has been published about the wildly conflicting extimates of $Q_{\infty}$ in circulation during recent years. 39,40 The controversy arose from the disparity between high ( 2000 TCf) estimates, typified by the 1972.U.S. Geological Survey (USGS) estimate, $^{41}$ and low ( 1000 Tcf) estimates, such as that of Hubbert. 21 some repetitive studies have cast doubt on all. current. methods of resource estimation. 42

In response to the accusation that its estimates were high, 40 the USGS launched a massive reestimation of U.S. oil and gas resources. The results, ${ }^{15}$ published in April 1975, are considerably lower than the 1972 estimates. They were obtained by a probabilistic approach that sets probability limits on all quantities estimated and is thus not subject to most of the criticisms leveled at current estimation methods. The lowered estimates seem to have quelled the controversy considerably and have satisfied even so vocal a critic as Hubbert. 43,44

For the lower 48 states, then, it is fairly safe to take the USGS lower estimatc of 1158 Taf for $Q_{w}$ (the so-ralled $95 \%$ certainty estimate) as a middle case. 'l'lis iu bracknted hy the median USGS estimate of 1280 Tcf and Hubbert's own estimate 21 of 1050 Tcf to provide a useful, if somewhat conservative, range. For Alaska, with its uncertainties, the USGS high, medium, and low figures of 179.6, 123.6, and 76.6 licf die as good as any available.

Table A-4 shows a typical projection obtained on this basis, and the options are shown graphlcally in Figures $A-7$ and $A-8$. Navigating middle courses through this kind of network diagram seems a reasonable method of establishing working figures for low, medium, and high scenarios of yas supply. Averaging the middle 
estimates for each $Q_{\infty}(1050,1158$, and 1280 TCf) produces, at the year 2000, estimates of 11.8, 15.3; and 17.9 Tcf production; any attempt to squeeze higher accuracy from this method is numerical foolishness. The final results are shown in Table $\mathrm{A}-5$.

\section{Table $A-5$}

\section{SUMMARY OF $\cdot Q$ PROJECTIONS (TCF) CLUSTER}

\begin{tabular}{|c|c|c|c|}
\hline & Low & Medium & $\mathrm{High}$ \\
\hline 1972 (actual) & 22.8 & 22.8 & 22.8 \\
\hline 1985 & $17.6 *$ & 22.6 & 25.8 \\
\hline 2000 & 11.8 & 15.3 & 17.9 \\
\hline
\end{tabular}

* FPC case II for lower 48 states. 


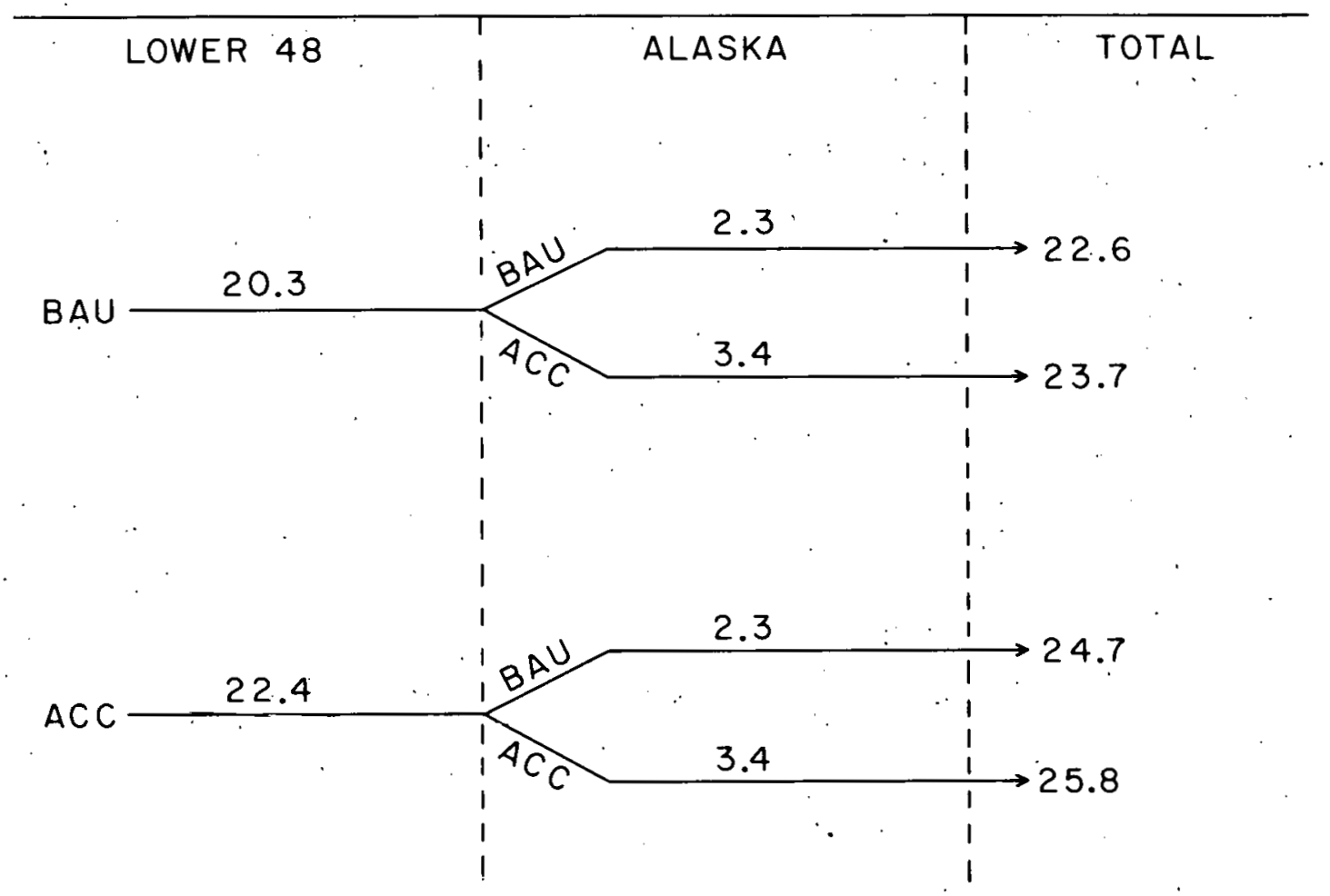

Figure A-7. 1985 projection options for project independence rases.

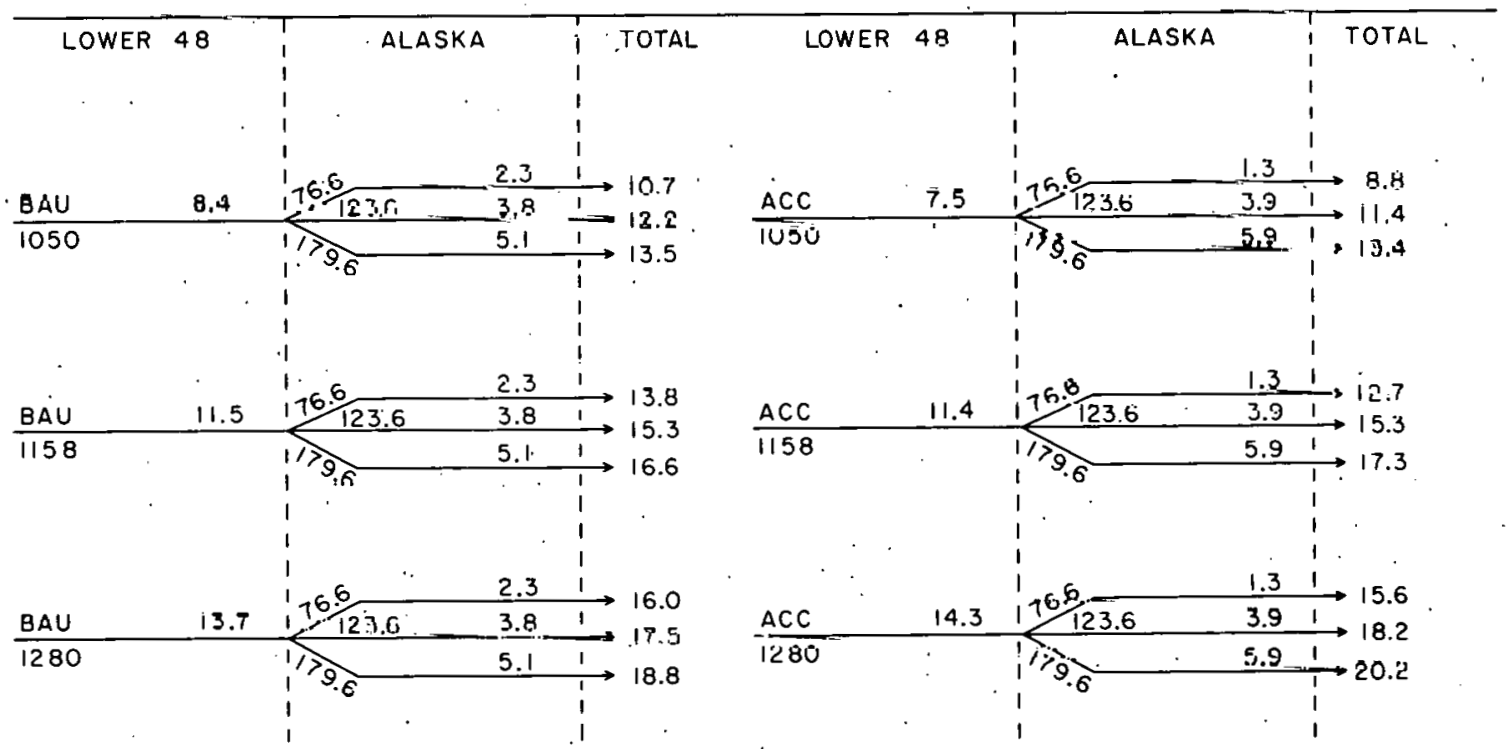

Figure A-8. Typical option diagram for year 2000 projections of marketed production. 


\section{APPENDIX B}

SOME CAUSES OF NATURAL GAS CURTAILMENT IN THE INTERSTATE MARKET

$$
\text { by T. H. MCCOY }
$$

The curtailment of natural gas in the interstate market has progressively worsened in the past few years. Since supply contracts between prodidcers and interstate pipelines are subject, to approval by the Federal power Commission (FPC) and are based on proven reserves rather than future discoveries of natural gas, it is by no means clear why producers should be unable to meet their contractual obligation and hence curtail their supply to interstate pipelines. An attempt is made here to answer this question partially by citing a few specific examples.

1. Reserves Dedicated to Contract Less Than Expected

Normally, a contract between a producer and a transmission company specifies the particular field from which gas will be supplied and the anount of gas reserve available. Problems sometimes occur when the amount of reserve proves to be less than expected, and, worse still, in some cases gas is expected to be supplied only from a general area and no specific reserves are dedicated. In either case, producers eventually become unable to meet the demand required by the contracts.

A good example of the latter situation is a certain contract between Gulf Uil Corporation and Texas Eastern Transmission Corporation $^{45}$ calling for deliveries of 500 million cubic feet (MMCf) per day. Since Texas Eastern received a daily average of only 398 MMCf in 1974 and 373 MMCf during the first six months of 1975, it has had to curtial its supply to distributors in 15 states from Texas to New York. In 1963, the FPC authorized Gulf Oil to sell 4.4 Tcf of gas to Texas Eastern over 26 years. No specific reserves were dedicated, although most of the gas was expected to cone from the West Delta 
Block in southern Louisiana. Gulf Oil estimated reserves in that field at about 2.7 Tcf and said it had additional gas available to fulfill, the contract. In 1971, when Gulf Oil determined that the West Delta Block reserves were less than expected, it sought to amend the contract but was denied by the FPC. Late in 1975, the FPC ordered Gulf Oil to present evidence on what had been done to meet the delivery obligations under its contract, to present, evidence on all new intrastate sales and emergency interstate sales begun by it under contracts on or after January 1, 1973, and to explain why the gas from each such sale was not dedicated to the performance of its contract with Texas Easten.

2. Failure to Develop Reserves

In order to maintain or increase the deliverability from a gas field with known reserves, it is necessary to drill additional wells. Producers sometimes fail to do so for a variety of reasons, the major one being economics. 46 The failure to develop reserves occurs in both onshore and offshore areas. For example, the FPC recently charged ${ }^{47}$ that Mobil oil Corporation, which operates several fields in the offshore Louisiana area, apparently has not been maintaining production by drilling a sufficient number of additiunal wello. In the meantime, two interstate pipelines (Continental Oil and Newmont $U_{i l}$ ) supplied hy Mobil oil have requested explanations for the decreases in gas production. The situation becomes more complicated when two or more producers operate a field jointly, as they cannot always agree on the need for drilling new wello. This also contributes to the lack of development of existing fields and the decrease of gas production. The portion of the Bastian Bay field operated by Getty oil Company and Tenneco Oil Company is an example. ${ }^{48}$ It started producing in 1962, and annual production reached its 
peak of about 160 Bcf in 1968, but by 1974 it fell to 64 Bcf. As a.consequence; United Gas Pipe Line and Tennessee Gas Pipeline, which are supplied by Getty Oil and Tenneco. Oil respectively, are faced with curtailment problems:

Garden City; another. large gas field in southern Louisiana, which is operated jointly by Exxon Corporation and Quintana Petroleum Corporation, seems to have similar problems. 49 This field has been producing for $>20$ years but still has at least 670 Bcf of gas reserves. Considering that the producing life of most gas fields is. between 15 and 25 years and that Columbia Gas Transmission. Corporation received only 38.5 Bcf rather than the anticipated $50 \mathrm{BCf}$ in 1974; it seems likely that the Garden. City field has not been properly developed.

3. Failure to Maintain Output From Producing Wells

A number of factors could affect the performance of producing wells. Decreased gas pressure, mechanical difficulties, repair work, and natural disasters are a few examples.

The pressure of a reservoir decreases as gas is produced, eventually going so low that compression is necessary to withdraw the remaining gas and feed it into a pipeline at a given pressure. Since interstate pipelines are usually operated at a higher pressure than some small local pipelines, compression is even more important to those reserves dedicated to the interstate market. The installation of complession tacilities is often specified in sales contracts between producers and pipelines. However, in: some cases, either party can install such facilities but neither is obligated to do so under the contract. Rather than installing compressors, sometimes the parties involved choose to terminate their contract before it expires. and the lendining low pressure gas is sold by the:producer on the local market while the pipeline faces a shortage of gas supply. 
In recent years a number of procedures and pipeline companies have been ordered by the FPC to. show cause why they did not violate the Natural Gas Act by abandoning sales, services, and facilities in such a fashion and without prior FPC authorization. Among them are a Texas producer, Bright and Schiff, and its gas pipeline purchaser, South Texas Natural Gas Gathering Company. 50 The latter resells the gas to Transcontinental Gas Pipe Line Corporation (Transco), which probably faced a greater shortage of gas during the winter of 1975-76 than any other major interstate pipeline. The gasiwell irvolvod in this case is Reynolds Number. One in whitted rield, Texas.

Florida Gas Transmission Company and its two producers, skelley Oil Company and Petroleum Management, Inc. (PMI), were also ordered by the FPC to show cause. 5.1 In 1956 the gas from the Arkansas Pass Field in Texas was dedicated to Florida Gas under a 20-year contract, and the two producers stopped deliveries in Deciember 1972 and January 1973 without FPC approval. 'Since then, PMI has been selling the low pressure gas to the Lo-Vaca Gathering Company, a local pipeline, on a day to day basis.

In both cases the pipeline companies were made respondents in the proceeding, because the FPC considers 50.51 the pipelines to be integral parts of interstate gas sales and therefore to have responsibilities under the Natural Gas Act to pursue all available administrative and judicial remedies with respect to the producers' failure to meet their delivery obligations under the contracts authorized by the FPC.

Another cause of declining gas production can be the unexpected, uncurtrollable encroachment of water into the wells, to thc point that further production becomes uneconomical. This kind of mechanical difficulty is fairly common in southern Louisiana. 49 In. offchore areas, wells could deteriorate because of corrosion. 52 
Natural disasters, such as hurricanes, $\stackrel{49}{9}$ also incapacitate gas wells. The extensive damage ${ }^{47,53}$ done by Hurricane Carmen in the summer of 1974 forced the shutdown of several large wells owned by Cities Service oil Company, Tenneco Oil Company, and Continental Oil Company, the first of which supplies Transco and the other two supply the Tennessee Gas Pipeline Company. The repair work lasted well into the following winter and caused a major increase of curtailments by Transco (an additional $15 \mathrm{BCf}$ ) and Tennessee Gas ( $13 \%$ instead of the projected $6 \%$ ).

In order to minimize waste and to protect the individual owners of wells that share a single reservoir, various states have rules limiting the rate of production. At times of peak demand, gas wells are usually permitted to produce more than the allowable amount, say $25 \%$, of the well's potential productive capacity, and the overproduction is then balanced during warm seasons when demand is low. However, in some cases 47 regulatory agencies have ordered wells shut down during the winter to compensate for overproduction and thus caused unnecessary. shortage and hardship. Another reason for shutdown is repair work on gas wells. Although unavoidable, major repairs and maintenance should be scheduled during seasons of low demand. Unfortunately the ideal does not always take place and unnecessary curtailment during the winter heating season can occur. 53

4. Diversion of Gas From Interstate to Intrastate Markets

Diversion could take various forms. Selling low pressure gas on the local market rather than installing compression facilities is one form. Selling Federal offshore gas to intrastate pipeline is another. According to the FPC, for example, 54 the Tenueco oil cumpany has, for the last few years, diverted $>2$ Bcf/year of offshnre gao from the l'ennessee Gas Pipeline Company to Creole Gas 
Pipeline Company, an intrastate Louisiana pipeline. In the meantime, the customers of Tennessee Gas were faced with curtailment.

\section{Conculsion}

The above limited effort to probe the causes of curtailment of natural gas on the interstate market is by no means conclusive or exhaustive. . Two further factors are worth pointing out.

a. Even though producers are under contractual obligations to deliver certain amounts of natural gas to interstate pipeline companies, the latter seem to be reluctant to take action against the profucers whill they are nnt meeting their obligations. Instead, the pipeline companies either simply pass the deficiency on to their customers by curtailment or make emergency purchases of natural gas, SNG, or LNG at considerably higher prices and pass the price differential on to their customers. In either case, it is the customers who .suffer. It is not clear why the pipelines rarely pursue administrative or judicial remedies with respect to the producers' failure to carry out the requirement of the contracts authorized by the FPC. Speculations regarding their reasons for inaction cover a wide range, from sheer incompetence to the chumminess often found within any one industry, and to deliberate efforts toward making largar profits. Both the FPC and the Congress have conducted some investigations in this area, ${ }^{47,55}$ although it is hard to tell whether there is truth in any of these allegations. However, one does wonder whether a contract means very much when both the pipeline and the producer are subsidiaries of the same holding company,* and whether one subsidiary could reasonably ue expcated to take the other to court.

\footnotetext{
*For example, the producer Tenneco Oil Company. and the interstate pipeline Tennessee Gas Pipeline Company, involved in some of the cases discussed above, are both owned by Tenneco, Inc.
} 
Unfortunately, the FPC apparently has not carried out its full responsibility in this regard either. 56 For example, even though the volume requirement is essential for maintaining deliverability, some contracts certified by the FPC have no specification of volume requirement. This came to light during a Congressional hearing in 1975, when the then FPC Chairman John Nassikas admitted that the FPC had no idea of the number of such contracts or of how long this practice has been going on.

b. As a result of the gas supply and demand situation, the FPC in October 1975 issued a policy statement ${ }^{57}$ reiterating its authority and intention to enforce gas deliverability as required by the Natural Gas Act. The statement "directs that future certificates issued by the FPC will be specifically conditioned to require companies to report to the FPC within 30 days of the initial reserve determination or any subsequent redetermination. Certificates will also be conditioned to require that if the company has not secured an appropriate certificate amendment and there are circumstances resulting in delivery of a lesser quantity of gas than any certified delivery obligation, the company shall file, for each contract year quarter; a verified report setting out the circumstances of the lesser deliveries and the corrective actions proposed to be undertaken to meet any experienced delivery deficiency. These verified reports are due within 10 calendar days after expiration of each contrart year quarter." It further states that the FPC will, "on its own motion, undertake appropriate enforcement proceedings, either within its own jurisdiction or the courts, to ensure compliance with gas delivery or production requirements under certificates it issues." 
Such a policy. statement, by itself, will not solve any problem. However, it does point out the direction in which the FPC will try to improve the gas shortage situation in the short term. And, as the curtailment of gas supply worsens, it will also help to give the society some idea of where the responsibilities lie. 
1. John Lee, Energy Supply and Demand in the Northeast United States, BNL 20427, Sept. 1975.

2. FPC* Releases state-by-State Summary of Gas Curtailments, News Release 21657, FPC, Aug. 20, 1975.

3. Survey of State Regulatory Agencies' and Intrastate Natural' Gas Suppliers Policies to Deal With the Natural Gas Shortage, National Association of Regulatory Utility Commissioners, Washington, D.C., 1974 .

4. The FEA Project Independence Boston Hearings, FEA, Nov. 1974.

5. Firm Curtailments, November 1974- March 1975, Private Communication, FEA.

6. FPC Releases Staff Report on. Actual and Projected Natural Gas Pipeline Curtailments, News Release 21878, FPC, Nov.11, 1975.

7. Consumer Energy Act of 1974, Hearings before the senate Committee on Commerce, Part V, Washington, D.C $\therefore 1974$.

8. Edward Cowan, Ford and critics jockey on oil prices, The New York Times; July 3, 1975.

9. Gasfacts, American Gas Association, Arlington, Va., 19.73.

10. Keith C. Brown, The case, for decontrolling gas producer prices, Public Utilities Fortnightly, p. 23 (May 8, 1975):

11. Task Force Report: Natural Gas, Project Independence BlueprinL, FEA, Nov. 1974, .

12. National Gas Survey, Vol. 1, FPC, 1973.

* FPC, Federal Power Commission, Washington, D.C.; FEA, Federal Energy Administration, Washington, D.C.; GPO, U.S. Government Printing Office, Washington, D.C. 
13. U.S. oil, gas drilling increased a record $20 \%$ in 1974 , group says, Wall Street Journal, Jan. 3, 1975.

14. A Realistic View of U.S. Natural Gas Supply, FPC, Dec. 1974.

15. B.M. Miller et al., Geological Estimates of Undiscovered Recoverable Oil and Gas Resources in the United States, Circ. 725, U.S. Geological Survey, April 1975.

16. OCS Oil and Gas, an Environmental Assessment, Vol. 1, Council on Environmental Quality, GPO, April 1974.

17. A National Plan for Energy Research, Development and Demonstration: Creating Energy Choices for the Future, ERDA-48, JuוE 1375.

18. U.S. Statistical Abstract, U.S. Department of Commerce, Washington, D.C., 1973.

19. Minerals Yearbook, U.S. Bureau of Mines, various years.

20. Energy Alternatives: A Comparative Analysis, Science and Public Policy Program, University of Oklahoma, GPO, May 1975.

21. M.K. Hubbert, U.S. Energy Resources, a Review as of 1972 , Committee on Interior and Insular Affairs, U.S. Senate, Washington, D.C., Serial No. 93-40 (92-75), 1974.

22. See, for example, various FPC news releases.

23. Gas Supply Indicators for the Third Quarter of 1975, News Release 22117, FPC, Feb. 2, 1976.

24. Task Force Report: Coal Project Iridepeindtiue Blueprint, FEA, Nov. 1974.

25. P.W. MacAvoy and R.S. Pindyck, Alternative regulatory policies for dealing with the natural gas shortage, Bell Journal of Economics and Management Science, 4. No. 2, 454 (1973).

26. R.S. Pindyck, The regulatory implications of three alternative econometr1c supply modela of natural gas, Ibid. 5, No. 2633 (1974).

27. E.A. Hudson and D.W. Jorgenson, U.S. energy policy and ecunomic growth, 1975-2000, Ibid., 461. 
28. C.E. Shittle and D.B. Reister, The IEA energy simulation model, pp. 49-52, Institute for Energy Analysis, Oak Ridge, Tenn., Jan. 1975.

29. S.F. Singer, Oil resource estimates, Science 188, 401 (1975).

30. Task Force Report: Natural Gas, Project Independence Blueprint, FEA, NOV. 1974 .

31. National Gas Survey, Vol. 1, Chap. 9, FPC, 1973.

32. U.S. Energy Outlook, a Report of the National Petroleum Council's Committee on Energy Outlook, NPC, Washington, D.C., Dec. 1972.

33. National Gas Supply and Demand, 1971-1990, FPC S-218, Feb. 1972 .

34. H.R. Linden, An Analysis of Potential production of Natural Gas in the United States, Institute of Gas Technology, Chicago, 1974.

35. H.R. Linden and J.D. Parent (Inst. Gas Technol.), Use of an economic incentive factor in the correlation and projection of discovery and production rates of natural gas in the lower 48 states, Paper SPE-4991, 49th Meet. Soc. Petroleum.Engineers, Houston, Oct. 1974 .

36. FPC Increases National Rate for Gas Producer Sales to 50 Cents on Rehearing, News Release 20909, FPC, Dec. 4, 1974.

37. National price set on interstate sale of natural gas, Wall Street Journal, June 24, 1974.

38. U.S. oil, gas drilling increased a record 20 percent in 1974 , Group says, Wall Street Journal, Jan. 3, 1975.

39. R. Gillette, Oil and gas resources: did USGS gush too high? Sripnce 105, 127 (1974).

40. R. Gillette, Oil and gas resources: academy calls USGS math "misleading", Science, 187, 724 (1975).

41. P.K. Theobald, and S.P. Schweinfurth, D.C. Duncan, Energy Resources of the: United States, U.S. Geological Survey, Circ. 650, 1972 .

42. F.R. Tuftc, (Princeton Univ.), How Useful Are Projections of Oil Resources? FEA, May 15, 1975. 
43. R. Gillette, Geological survey lowers its sights, Science 189,200 (1975).

44. Edward Cowan, Expert doubts U.S. can substantially cut oil imports by 1985, The New York Times, July 8,'1975.

45. Energy Users Report (EUR) (The Bureau of National Affairs, Inc., Washington, D.C.) No. 118, p. A-5 (11/13/75).

46. EUR No. 117, p. $A-43,(11 / 6 / 75)$.

47. EUR No. 122 , p. A-1, (12/11/75).

48. EUR No. 120, p. A-26, (11/27/75) .

49. EUR No. 117, p. A-41; $(11, / 6 / 75)$.

50. EUR No. 118, p. A-26, (11/13/75).

51. EUR No. 120 , p. A-1, (11/27/75).

52. EUR No. 99, p. A-8, (7/3/75).

53. EUR No. 110, p. A-24, (9/18/75).

54. EUR No. 128, p. A-15, (1/22/76).

55: EUR NO. 123, p. A-5, $(12 / 18 / 75)$.

56. EUR NO. 112, P. A-3, (10/2/75).

57. FPC Issues Statements of Policy on Enforcement of Gas Deliverability, News Relearc 21804, FPC, Oct. 14, 1975. 


\section{THE BROOKHAVEN NATIONAL LABORATORY REGIONAL ENERGY STUDIES PROGRAM}

The Brookhaven National Laboratory Regional Energy Studies Program is part of a national effort supported by the U.S. Energy Research and Development Administration (ERDA) to create an energy assessment capability which is sensitive to regional conditions, perceptions, and impacts. Within ERDA, this program is supported by the Division of Biomedical and Environmental Research and includes, in addition to a concern for health and environmental impacts of energy systems, analysis of the complex trade-offs between economics, environmental quality, technical considerations, national security, social impacts, and institutional questions. The Brookhaven Program focuses on the Northeast, including the New England states, New York, Pennsylvania, New Jersey, Maryland, Delaware, and the District of Columbia. The content of the program is determined through an identification of the major energy planning issues of the region and in consultation with state and reglonal agencies. A major component of the program in 1976 is the Northeast Energy Perspectives Study which examines the implications of alternative energy supply-demand possibilities for the region. 